\title{
Evaluation of the Anticonvulsant, Anxiolytic, Sedative, and Neuroprotective Activities of Polysaccharides from Mycelium of Two Ganoderma Species
}

\author{
Verónica Núñez-Urquiza, ${ }^{1}$ Juana Villeda-Hernández, ${ }^{2}$ Elizur Montiel-Arcos, ${ }^{3}$ Isaac Tello, ${ }^{3}$ Victoria Campos-Peña, ${ }^{2}$ \\ Maribel Herrera-Ruiz, ${ }^{4}$ María del Carmen Gutiérrez, ${ }^{5}$ Vera Petricevich, ${ }^{6}$ María Angélica Santana, ${ }^{7}$ Martha Navarro, ${ }^{2}$ \\ Angélica Berenice Aguilar-Guadarrama, ${ }^{1}$ Gabriel Navarrete-Vázquez, ${ }^{8}$ Irene Perea-Arango, ${ }^{5}$ Ismael León-Rivera ${ }^{1} * *$
}

Verónica Núñez-Urquiza, ${ }^{1}$ Juana VilledaHernández, ${ }^{2}$ Elizur Montiel-Arcos, ${ }^{3}$ Isaac Tello, ${ }^{3}$ Victoria Campos-Peña, ${ }^{2}$ Maribel Herrera-Ruiz ${ }^{4}$ María del Carmen Gutiérrez, ${ }^{5}$ Vera Petricevich, ${ }^{6}$ María Angélica Santana, ${ }^{7}$ Martha Navarro, ${ }^{2}$

Angélica Berenice Aguilar-Guadarrama, Gabriel Navarrete-Vázquez, ${ }^{8}$ Irene PereaArango, ${ }^{5}$ Ismael León-Rivera ${ }^{1, *}$

'Centro de Investigaciones Químicas, IICBA Universidad Autónoma del Estado de Morelos, Avenida Universidad 1001, Col. Chamilpa 62209 Cuernavaca, Morelos, Estados Unidos Mexicanos, MEXICO.

2Instituto Nacional de Neurología y Neurocirugía Manuel Velasco Suárez. Avenida Insurgentes Sur No. 3877 Col La Fama Tlalpan, Ciudad de Mexi No. 3877 Col. La Fama Tlalpan, Ciudad de México, Estados Unidos Mexicanos.

${ }^{3}$ Centro de Investigaciones Biológicas,

Universidad Autónoma del Estado de Morelos, Avenida Universidad 1001, Col. Chamilpa 62209 Cuernavaca, Morelos, Estados Unidos Mexicanos. ${ }^{4}$ Centro de Investigación Biomédica del Sur, Instituto Mexicano del Seguro Social, Argentina 1, Col. Centro, Xochitepec, Morelos, Estados Unidos Mexicanos. ${ }^{5}$ Centro de Investigación en Biotecnología, IICBA Universidad Autónoma del Estado de Mor Universidad Autónoma del Estado de Morelos, Avenida Universidad 1001, Col. Chamilpa 62209 Cuernavaca, Morelos, Estados Unidos Mexicanos. ${ }^{6}$ Facultad de Medicina, Universidad Autónoma del Estado de Morelos, Avenida Universidad 1001, Col. Chamilpa 62209 Cuernavaca, Morelos, Estados Unidos Mexicanos.

${ }^{7}$ Centro de Investigación en Dinámica Celular, IICBA, Universidad Autónoma del Estado de Morelos, Avenida Universidad 1001, Col. Chamilpa 62209 Cuernavaca, Morelos, Estados Unidos Mexicanos. ${ }^{8}$ Facultad de Farmacia, Universidad Autónoma del ${ }^{8}$ Facultad de Farmacia, Universidad Autónoma de Estado de Morelos, Avenida Universidad 1001, Col.
Chamilpa 62209 Cuernavaca, Morelos, Estados Unidos Mexicanos.

\section{Correspondence}

\section{Ismael León-Rivera}

Centro de Investigaciones Químicas,

IICBA, Universidad Autónoma del Estado de Morelos, Avenida Universidad 1001,

Col. Chamilpa 62209 Cuernavaca, Morelos, Estados Unidos Mexicanos, MEXICO.

E-mail: ismaelr@uaem.mx

History

- Submission Date: 07-05-2021;

- Review completed: 13-06-2021;

- Accepted Date: 23-06-2021.

DOI : 10.5530/pj.2021.13.149

Article Available online

http://www.phcogj.com/v13/i5

Copyright

(C) 2021 Phcogj.Com. This is an openaccess article distributed under the terms of the Creative Commons Attribution 4.0 International license.

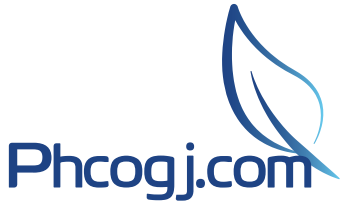

\begin{abstract}
Background. Ganoderma lucidum has been used as a medicinal mushroom since centuries in East Asia. Recent reports have shown that metabolites isolated from Ganoderma species have shown effects on central nervous system. Objective. To determine the neuroprotective, anticonvulsant, anxiolytic, and sedative effects of Ganoderma sp. and Ganoderma curtisii polysaccharides. Methods. Polysaccharides (Gsp-PS2 or Gc-PS2) were isolated from two Ganoderma mycelia submerged cultures. Acute toxicity effects of Gc-PS2 or Gsp-PS2 on mice were treated orally with doses of $50-2000 \mathrm{mg} / \mathrm{kg}$. Anticonvulsant activity was determined using three chemoconvulsants: kainic acid (KA), strychnine, or pentylenetetrazole (PTZ). Anxiolytic-like effects were determined using the elevated plus maze test on mice. GABA release evoked by GC-PS2 or Gsp-PS2 content was determined by HPLC. Neuroprotective effects of Gsp-PS2 or Gc-PS2 were determined by glial activation, histopathological changes, and immunohistochemistry. Results. Gc-PS2 or Gsp-PS2 showed neuroprotective activity by diminishing neuronal death, reducing glial activation and Neu-N expression levels. Gsp-PS2 or Gc-PS2 inhibited convulsions in the KA model. An anxiolytic-like, but not a sedative effect was reported in mice treated with Gc-PS2 or Gsp-PS2 Polysaccharides Gc-PS2 or Gsp-PS2 evoked endogenous GABA release and increased its concentration within the incubation medium. Pretreatment with Gsp-PS2 or Gc-PS2 showed a reduction of the LPSinduced NO production. Gc-PS2 or Gsp-PS2 did not produce toxic effects. Conclusion. Ganoderma sp. or Ganoderma curtisii polysaccharides showed neuroprotective and anticonvulsant activities in animal models. The anticonvulsant activity may involve the GABAergic neurotransmision.
\end{abstract}

Key words: Ganoderma sp, Ganoderma curtissi, a- and b-glucan, Neuroprotective, Anticonvulsant, GABA.

\section{INTRODUCTION}

Epilepsy is one of the most common serious neurological conditions and rises with older age. In recent times, several million persons worldwide suffer from epilepsy, and $20-30 \%$ of those afflicted have seizures that are resistant to treatment with the currently available antiepileptic drugs (gabapentin, lamotrigine, tiagabine, topiramate, or vigabatrin, for instance). ${ }^{1}$ Studies on the epilepsy have been done in several experimental models. However, they have all been shown to be effective in short-term add on clinical trials in patients with uncontrolled epilepsy. Therefore, phytomedicines (from plants or mushrooms) can potentially play an important role in the development of new antiepileptic drugs.

Ganoderma lucidum has been used for centuries in East Asia, as a popular folk medicine to treat various human diseases. The diversity of bioactive ingredients in G. lucidum is associated with its multiple pharmacological effects. Recent studies have shown the effect of G. lucidum on central nervous system illness. G. lucidum has been used as a tranquilizing agent for the treatment of insomnia and restlessness. G. lucidum extract has been reported to potentiate the anesthetic effect of pentobarbital, reducing spontaneous locomotor activity, and prolonging sleep time in rodents. ${ }^{2}$

Polysaccharides isolated from G. lucidum fruiting bodies and spores have shown neuroprotective properties such as: induced neuronal differentiation, decreased inflammatory mediator production by activated microglia, and protected dopaminergic neurons against inflammatory damage. ${ }^{3}$ In another study, polysaccharides isolated from G. lucidum mycelium reported a neuroprotective effect by diminishing the induction of proinflammatory cytokines. $^{4}$

Few studies have been reported to assess the anticonvulsant activity of Ganoderma metabolites. In our continuing study of Basidiomycetes with medicinal properties, the present research was designed to evaluate the neuroprotective, anticonvulsant, anxiolytic, and sedative activity of polysaccharides produced by submerged culture of two Ganoderma species collected in Mexico using animal models.

\section{MATERIALS AND METHODS}

\section{Mushrooms}

Ganoderma sp. fruiting bodies were collected on living trees of Ipomoea pauciflora, in a deciduous forest of Sierra de Huautla, Morelos, Estados Unidos
Cite this article: Núñez-Urquiza V, Villeda-Hernández J, Montiel-Arcos E, Tello I, CamposPeña $V$, Herrera-Ruiz $M$, et al. Evaluation of the Anticonvulsant, Anxiolytic, Sedative, and Neuroprotective Activities of Polysaccharides from Mycelium of Two Ganoderma Species. Pharmacogn J. 2021;13(5): 1161-1173. 
Mexicanos. Ganoderma curtisii fruiting bodies were collected from a temperate forest in the state of Morelos, Estados Unidos Mexicanos. Ganoderma sp. and Ganoderma curtisii basidiocarps were deposited in the Mushroom Herbarium at Centro de Investigaciones Biológicas, Universidad Autónoma del Estado de Morelos, Estados Unidos Mexicanos (vouchers COBIOCh-UAEMOR-CF-GSP01; COBIOChUAEMOR-CF-G01).

\section{Polysaccharides isolation}

Ganoderma sp. or Ganoderma curtisii mycelium was maintained on potato dextrose agar (PDA) at $27^{\circ} \mathrm{C}$. The inoculum consisted of five $1 \mathrm{~cm}$ cuts of 7-day old culture of each mycelium, cultivated on PDA. After the inoculation on $100 \mathrm{~mL}$ liquid substrate, the biomass was cultivated on rotatory shaker for ten days in $250 \mathrm{~mL}$ Erlenmeyer flasks $\left(\mathrm{N}=200 \mathrm{rpm}, 30^{\circ} \mathrm{C}\right)$. Mycelium was separated from the culture broth by filtration. The filtered cultivation containing extracellular polysaccharides was concentrated by lyophilization. The residue was re-dissolved in water and filtrated on a membrane $(0.45 \mu \mathrm{m}$, Millipore $)$, yielding the soluble polysaccharide fraction Gsp-PS2 or Gc-PS2. ${ }^{5}$

\section{Phytochemical screening of Gsp-PS2 or Gc-PS2}

Preliminary phytochemical screening of Gsp-PS2 or Gc-PS2 was performed for the detection of the chemical constituents: alkaloids, steroids, terpenoids, flavonoids, phenolics, saponins, carbohydrates, proteins, and amino acids. ${ }^{6}$ After obtaining the positive result for carbohydrates, the sugar composition of Gsp-PS2 or Gc-PS2 (40 mg) was determined by acidic hydrolysis with $0.5 \mathrm{M}$ trifluoroacetic acid for $5 \mathrm{~h}$. After this time, the aqueous phase from the acid hydrolysis reaction was neutralized with $\mathrm{Na}_{2} \mathrm{CO}_{3}$ solution and lyophilized to give a white solid. Furthermore, the residue was dissolved in $\mathrm{CH}_{3} \mathrm{CN}$ and analyzed by the HPLC system fitted with a $\mathrm{NH}_{2}$ column (Supelco, 250 $\mathrm{mm} \times 10 \mathrm{~mm} ; 10 \mu \mathrm{m})$, an isocratic elution of $\mathrm{CH}_{3} \mathrm{CN}: \mathrm{H}_{2} \mathrm{O}(85: 15 \mathrm{v} / \mathrm{v})$, at a flow rate of $1 \mathrm{~mL} / \mathrm{min}$, and a sample injection of $100 \mu \mathrm{L}(4 \mathrm{mg} /$ $\mathrm{mL}$ ) of standard carbohydrate solutions. Identification of the sugar components was performed by coelution experiments with standard samples (galactose, glucose). The HPLC system consisted of an Agilent HPLC system, fitted a 1100 series pump, Rheodyne injector, and a 1100 variable wavelength UV-Vis detector at $210 \mathrm{~nm}$. Characterization of Gsp-PS2 was performed by Nuclear Magnetic Resonance and Mass Spectrometry. A sample of Gsp-PS2 $(20 \mathrm{mg})$ was dissolved in $\mathrm{D}_{2} \mathrm{O}$ $(0.6 \mathrm{~mL})$ and then analyzed by NMR using an Agilent $400 \mathrm{NMR}$ spectrometer. One- $\left({ }^{1} \mathrm{H},{ }^{13} \mathrm{C}\right.$, and DEPTQ) and two-dimensional NMR (COSY and HSQC) experiments were obtained with a $5-\mathrm{mm}$ probe at $25^{\circ} \mathrm{C}$. Proton chemical shifts were referenced to the residual signal for HDO. Positive-ion HRMALDITOF MS data of Gsp-PS2 was acquired using a Shimadzu LCMS 8030 spectrometer, equipped with a laser of nitrogen at $337 \mathrm{~nm}$. The analyte was concentrated using Zip Tip C18 (Millipore), eluted with a solution $\left(80 \% \mathrm{v} / \mathrm{v} \mathrm{CH}_{3} \mathrm{CN} / 0.5 \%\right.$ trifluoroacetic acid) saturated with $\alpha$-cyano4-hydroxycinnamic acid (Sigma), applied on the metallic sample plate, dried, and analyzed in reflector mode. ${ }^{5}$

\section{Animals}

Male Wistar rats, 7 - 8 weeks old were purchased from Harlan (Mexico), weighting between 250 and $300 \mathrm{~g}$. Rats were randomly assigned to the experimental groups, and housed at Laboratorio de Enfermedades Neurodegenerativas, Instituto Nacional de Neurología y Neurocirugía. Adult ICR male mice (20-30 g) were purchased from ENVIGO RMS Co. While ICR mice were organized randomly in groups of seven animals, and were housed at Centro de Investigación Biomédica del Sur, IMSS. All animals were under controlled conditions (at least 3 weeks prior to experimentation), with a $12 \mathrm{~h}$ dark/light cycle, at a temperature of $20 \pm 1{ }^{\circ} \mathrm{C}$, with free access to food and water.
Animal experiments were conducted according to the Official Mexican Norms (NOM-062-ZOO-1999 and NOM-033-SAG/ZOO-2014) and the Code of Practice for the Housing and Care of Animals Used in Scientific Procedures. The experimental protocol (no. 113/09) was approved by the Ethics Committee of Instituto Nacional de Neurología y Neurocirugía.

\section{Acute toxicity test}

Acute toxicity of Gc-PS2 or Gsp-PS2 was evaluated according to the method described by Organization of Economic Cooperation and Development Guideline 420 (2002). The animals were kept fasting for overnight providing only water. The polysaccharides Gc-PS2 or Gsp-PS2 was administered orally at a dose of $5 \mathrm{mg} / \mathrm{kg}$ (suspended in $0.5 \%$ carboxymethyl cellulose) initially to separate groups of rats and mortality was observed for 3 days. If mortality was observed in $4 / 6$ or $6 / 6$ animals, then the dose administered was considered as toxic dose. However, if the mortality was observed in only 1 experimental animal out of 6 animals, then the same treatment was repeated with higher doses such as 50,300,500,1 000, and $2000 \mathrm{mg} / \mathrm{kg}$ orally. The control animals were given $10 \mathrm{~mL} / \mathrm{kg}$ of water. Animals were observed for behavioral changes and mortality within $24 \mathrm{~h}$. After this, daily observations for toxicity and mortality were made up to the 14th day.

\section{Anticonvulsant activity}

Chemoconvulsants: kainic acid (KA; Sigma Chemical Co., St. Louis, MO, U.S.); pentylenetetrazol (PTZ; Sigma Chemical Co., St. Louis, MO, U.S.A.); strychnine (Sigma Chemical Co., St. Louis, MO, U.S.) and polysaccharides (Gsp-PS2 or Gc-PS2) were dissolved in $2.5 \%$ Tween 20 solution and administered intraperitoneally (i.p.) to animals. Preliminary experiments performed in our laboratory demonstrated that $10 \mathrm{mg} / \mathrm{kg} \mathrm{KA}, 85 \mathrm{mg} / \mathrm{kg} \mathrm{PTZ}$, or $2 \mathrm{mg} / \mathrm{kg}$ strychnine was the minimal dose that resulted in behavioral seizure activity in all naive animals. $^{5}$ Anticonvulsant activity of Gsp-PS2 or Gsp-PS2 was determined at doses of 10,40 , or $80 \mathrm{mg} / \mathrm{kg}$. Chemoconvulsants or polysaccharides were dissolved in $2.5 \%$ Tween 20 solution and animals were separated in groups ( 5 rats per group): Control group received 2.5\% Tween 20 solution; Polysaccharide groups were administered GspPS-2 or Gc-PS2 at doses 10, 40, or $80 \mathrm{mg} / \mathrm{kg}$; Chemoconvulsant group received $10 \mathrm{mg} / \mathrm{kg} \mathrm{KA}$, or $85 \mathrm{mg} / \mathrm{kg} \mathrm{PTZ}$, or $2 \mathrm{mg} / \mathrm{kg}$ strychnine; Polysaccharide + chemoconvulsant group received Gsp-PS2 or Gc-PS2 at doses 10,40 , or $80 \mathrm{mg} / \mathrm{kg}$, and 2 days later the chemoconvulsant (10 $\mathrm{mg} / \mathrm{kg} \mathrm{KA}$, or $85 \mathrm{mg} / \mathrm{kg} \mathrm{PTZ}$, or $2 \mathrm{mg} / \mathrm{kg}$ strychnine). The time from injection of each chemical convulsant to the first appearance of seizure activity was measured for each animal and is referred to as the seizure latency. After administration of KA, this was the time to the first wetdog shake. For all the chemical-induced seizures, the total duration of the behavioral seizure activity also was measured for each animal.

Animals of each group after the treatment administration were placed separately into transparent plexiglas cages $(25 \times 15 \times 10 \mathrm{~cm})$ and monitored for up $60 \mathrm{~min}$ in order to evaluate the time of seizure onset, by a video tracking system. The severity of seizures was classified into five stages: stage 1, characterized by facial movements; stage 2, characterized by head nodding and myoclonic twitching; stage 3, characterized by forelimb clonus with lordotic posture; stage 4, characterized by forelimb clonic seizures with reared posture, stage 5 , characterized by tonic-clonic seizures without postural control; and stage 6 , characterized by death of rats. In the present study rats exhibiting at least stage 3 , were considered positive for seizure onset. ${ }^{5,7}$

\section{Anxiolytic test}

The Elevated Plus Maze (EPM) test is the most frequently employed model for the assessment of the antianxiety activity of substances. The EPM apparatus consisted of two open arms $(25 \times 10 \mathrm{~cm})$ and two 
enclosed arms $(25 \times 10 \times 15 \mathrm{~cm})$ with an open roof. The two open amas are intersected by two perpendicularly opposing closed arms with a central square. The entire maze was constructed of wood and elevated $20 \mathrm{~cm}$ above floor. Animals were divided into five groups, each group comprised six rats. Different groups were treated with distilled water $(10 \mathrm{~mL} / \mathrm{kg})$, diazepam $(5 \mathrm{mg} / \mathrm{kg})$, and Gsp-PS2 or Gc-PS2 at doses of 125,250 , and $500 \mathrm{mg} / \mathrm{kg}$. Thirty minutes later, the animal was placed in the center platform of the maze facing the open arm and was observed for $10 \mathrm{~min}$. An entry into an arm was defined as the animal placing all four paws over the line marking that area. The number of entries and the time spent in the open and closed arms were recorded during a 5 min test period. The percentage of open arm entries (100 xopen / total entries) was calculated for each animal. After each test, the maze was carefully cleaned up with a $70 \%$ ethanol solution, to eliminate the interference of the olfactory cues left by the previous animal.

\section{Assessment of sedative activity}

Mice were divided into three groups: Group A was treated with $10,20,40$, and $80 \mathrm{mg} / \mathrm{kg}$ i.p. of Gc-PS2 or Gsp-PS2 dissolved in 2.5 $\%$ Tween solution; Group B received diazepam dissolved in $2.5 \%$ Tween solution $(1.0 \mathrm{mg} / \mathrm{kg}$, i.p.) as positive control; Group C served as the control and received the vehicle $2.5 \%$ Tween 20 solution (100 $\mathrm{mL} / 10 \mathrm{~g}$ ) i.p. Animals were pretreated with Gc-PS2, or Gsp-PS2, or vehicle, or diazepam. Sixty minutes later, sodium pentobarbital was administered intraperitoneally (a sub-hypnotic dose, $30 \mathrm{mg} / \mathrm{kg}$ ). Mice were immediately placed individually in a transparent plexiglas box for the onset of uncoordinated movements (sedative effect) and for sleep duration.

\section{Open field test}

The apparatus was made up of plywood measuring $72 \mathrm{~cm} \times 72 \mathrm{~cm} \times 36$ $\mathrm{cm}$. One of the walls was made of transparent Perspex glass to ensure that the mouse under investigation is visible to the observer. The floor, made of cardboard, was divided into 16 equal squares $(18 \mathrm{~cm} \times 18$ $\mathrm{cm}$ ) with blue marker and a central square drawn with black marker. The cardboard was covered with a transparent Plexiglas. The animals were divided into five groups; each group comprised six rats. Different groups were treated with distilled water $(10 \mathrm{~mL} / \mathrm{kg})$, diazepam $(5 \mathrm{mg} /$ $\mathrm{kg}$ ), Gc-PS2 or Gsp-PS2 at doses of 250 and $500 \mathrm{mg} / \mathrm{kg}$. Thirty minutes later, each mouse was placed individually at the corner of the arena and its behavior monitored for $5 \mathrm{~min}$. The number of rearing, ambulation, and central locomotion by each mouse was recorded. The apparatus was wiped between observations with $70 \%$ ethyl alcohol and allowed to dry to remove any olfactory cue.

\section{GABA release assay}

Mice were sacrificed by cervical dislocation and brain dissection was performed on a plate with crushed ice. Subsequently, cortex slices $(250-300 \mu \mathrm{m})$ were manually obtained with a razor blade and guide coverslips. For each condition, a cerebral cortex slice $(500-600 \mu \mathrm{g})$ was placed in $2 \mathrm{ml}$ of modified Krebs-Ringer buffer (basal medium): (120.0 mM NaCl, $4.7 \mathrm{mM} \mathrm{KCl}, 1.8 \mathrm{mM} \mathrm{CaCl}_{2}, 0.8 \mathrm{mM} \mathrm{MgSO}_{4}, 1.0$ $\mathrm{mM}$ Tris- $\mathrm{HCl}$ buffer $\mathrm{pH}$ 7.4) and $10.0 \mathrm{mM}$ glucose ( $\mathrm{pH}$ 7.4) previously oxygenated with bubbling $\mathrm{O}_{2}$. Amino-oxyacetic acid, $10.0 \mathrm{mM}$, was added to the medium to prevent GABA metabolism.

Cerebral cortex slices were placed into in vial with $2 \mathrm{ml}$ of basal medium at $37{ }^{\circ} \mathrm{C}$ during $10 \mathrm{~min}$ with constant aeration. No substance was added to the control group. Gc-PS2 or Gsp-PS2 were added at a final concentration of $10.0 \mu \mathrm{g} / \mathrm{mL}$ or $20 \mu \mathrm{g} / \mathrm{mL}$. The positive control group was administered $47 \mathrm{mM} \mathrm{KCl}$. Aliquots of $200 \mu \mathrm{L}$ were taken out at 0.5 , $1.0,1.5,2.0$, and $3.0 \mathrm{~min}$, and store at $-20^{\circ} \mathrm{C}$ for GABA measurement.

\section{GABA quantification}

GABA content of samples was determined by HPLC on a Merck Hitachi liquid chromatograph equipped with a fluorescence detector (wavelength of $330 \mathrm{~nm}$ of excitation and $450 \mathrm{~nm}$ of emission), using a Cartridge-LiChorospher ${ }^{\circ} 100 \mathrm{RP}-\mathrm{C} 18$ chromatographic column of 5 $\mu \mathrm{m}$ particle size, and a linear gradient of $80 \%$ solvent $\mathrm{A}\left(\mathrm{CH}_{3} \mathrm{COONa}\right.$ $0.1 \mathrm{M}, \mathrm{pH} 7.0)$ to $100 \%$ solvent $\mathrm{B}\left(\mathrm{CH}_{3} \mathrm{OH}\right)$ along $10 \mathrm{~min}$ with a flow of $1.5 \mathrm{ml} / \mathrm{min} .20 \mu \mathrm{l}$ of each collected aliquot was previously derivatized with O-phthaldialdehyde (OPA, Merck-Schuchardt). Quantification of GABA was achieved using a standard curve of known concentrations of GABA (Sigma Aldrich) derivatized. Protein content in brain slices was determined after its homogenization in $1 \mathrm{ml}$ of water according to the Lowry, using bovine serum albumin (BSA, Irvine Scientific) as protein calibration. GABA concentration in each aliquot was expressed as pmol of GABA/ $\mu \mathrm{g}$ of protein. ${ }^{8}$

\section{Immunohistochemistry}

Two days after treatments, animals were deeply anesthetized with pentobarbital $(40 \mathrm{mg} / \mathrm{kg}$, intraperitoneally) and then transcardially perfused with cold and sterile saline solution $0.9 \%$, followed by 4\% Phosphate-Buffered Paraformaldehyde. Brains were removed and stored for 1 week in a solution with $4 \%$ Phosphate-Buffered Paraformaldehyde and $4 \%$ of sucrose. Brains were dehydrated in gradual alcohols $(70 \%, 96 \%$, and $100 \%)$, followed by xylene treatment and paraffin embedded. $8 \mu \mathrm{m}$-thick sagittal serial slices were obtained, and the slides were deparaffinized and hydrated. Antigen recovery was performed with $0.1 \mathrm{M}$ citrate buffer, $\mathrm{pH} 6$ and $0.2 \%$ Triton at $60^{\circ} \mathrm{C}$ for $12 \mathrm{~min}$. Endogenous peroxidase was inactivated with blocking reagent (Dako-Agilent Santa Clara, USA) for $10 \mathrm{~min}$. Additionally, the tissue was incubated with bovine serum albumin (BSA) $2 \%$-Triton $0.2 \%$ for $15 \mathrm{~min}$. Slides were blocked with Background Sniper (Biocare Medical, California USA) for $15 \mathrm{~min}$. Primary antibodies were diluted in BSA $1 \%$ and incubated at $4^{\circ} \mathrm{C}$ overnight, followed by incubation Mach2 Universal HRP-Polymer Detection (Biocare Medical, California USA) for $30 \mathrm{~min}$. Slides were mounted and analyzed on a Leica DM LS microscope (Leica Microsystems, Wetzlar, Germany). Primary antibodies diluted in BSA $1 \%$ were incubated at $4^{\circ} \mathrm{C}$ overnight, followed by secondary antibody incubation for $1 \mathrm{~h}$ at room temperature. Slides were mounted with Vectashield antifade mounting medium (Vector Laboratories, California, USA, H-1000). Images were captured on a Leica TCS SP8 confocal microscope and processed with LAS AF software (Leica Microsystems). Primary antibodies used were: mouse monoclonal anti-NeuN (1:200, Millipore, Merck KGaA, Darmstadt, Germany), rabbit polyclonal anti-GFAP (1:150, Genetex, California USA). Sections containing hippocampus and cortex regions of each rat in each group were set for staining with hematoxylin and eosin and observed by light microscopy. ${ }^{5}$

\section{Effect of GC-PS2 or Gsp-PS2 on nitric oxide (NO) release}

Microglia were isolated and purified from brains of 12-24-h-old Wistar rats. After brains were dissected and the meninges removed, the tissues were minced and digested with trypsin $(0.25 \%$ trypsinEDTA in $0.1-\mathrm{M}$ phosphate buffer) for $20 \mathrm{~min}$ at $37^{\circ} \mathrm{C}$, triturated with a fire-polished Pasteur pipette and filtered through a $200-\mathrm{mM}$ nylon cell strainer. After centrifugation for $5 \mathrm{~min}$ at $121 \mathrm{~g}$, the tissue was suspended into DMEM containing 10\% fetal bovine serum (FBS) and seeded in $75 \mathrm{~cm}^{2}$ flasks at a density of $6 \times 10^{4} / \mathrm{ml}$ cells per flask. Two weeks after the seeding, the flasks were shaken at $180 \mathrm{rpm}$ for $4 \mathrm{~h}$, and the floating cells were collected and centrifuged for $5 \mathrm{~min}$ at $800 \mathrm{rpm}$, the cells were resuspended and plated to 96-well plates for further experimental treatment. The cultures of microglia were treated for $24 \mathrm{~h}$ with lipopolysaccharide (LPS, $0.25 \mathrm{mg} / \mathrm{ml}$ ) as a positive control, GspPS2 or Gc-PS2 polysaccharides $(50-300 \mu \mathrm{g} / \mathrm{ml})$. 


\section{NO Assay}

The production of NO was quantified by measuring the released NO metabolites (nitrates and nitrites) with Griess reagent. After a 24 $\mathrm{h}$ exposure to LPS/cell fraction, the culture medium samples were collected and prepared cell-free by centrifugation. The NO released by cells to the culture medium was determined by Griess reaction method. In brief, the collected medium was incubated with nitrate reductase to reduce nitrate to nitrite. Then, $12.5 \mathrm{mM}$ sulfanamide in $6 \mathrm{~N} \mathrm{HCl}$ and $12.5 \mathrm{mM} \mathrm{N}$-(1-naphtyl) ethylenediamine were added to the nitrite solution to complete the azo coupling reaction. The absorbance of the final product was measured at $\lambda=530 \mathrm{~nm}$.

\section{Statistical evaluation}

The latency to seizure onset, seizure duration, and seizure score were averaged across animals in the same treatment group. Comparisons between groups were done with an analysis of variance (ANOVA) with nonparametric measures (Kruskal-Wallis) and post hoc test (Dunn's) with comparison with chemical convulsant alone. A statistical difference was determined by a value of $p<0.05$. For anxiolytic and potentiation assays an Analysis of variance (ANOVA) with a confidence level of 95\% $\left({ }^{*} p \leq 0.05\right)$ and followed a one tailed Dunnett test ${ }^{*} p \leq 0.05$ in comparison with the VEH group -the negative control-.

\section{RESULTS}

\section{Phytochemical analysis of Gsp-PS2}

In order, to characterize the polysaccharide soluble fractions GspPS2 or Gc-PS2 we conducted a preliminary phytochemical analysis. The chemical tests used for preliminary phytochemical analysis of these polysaccharides indicated that no terpene, triterpene, flavonoid, saponin, nor aminoacid compounds were detected in this fraction. The only positive test was for saccharides. Sugar compositional analysis of Gsp-PS2 or Gc-PS2 was performed by acid hydrolysis of polysaccharides and HPLC analysis of the hydrolyzed, indicated that polysaccharides were composed by glucose units $\left(t_{R}=12.2 \mathrm{~min}\right)$.

The ${ }^{1} \mathrm{H}$ and ${ }^{13} \mathrm{C}$ DEPTQ NMR spectra (figures 1 and 2 ) corroborated that Gsp-PS2 consists of a saccharide entity. The chemical shifts of the saccharide unit were established by $1 \mathrm{D}$ and 2D NMR spectra of Gsp-PS2 (figures 1,2,3). The ${ }^{1} \mathrm{H}-\mathrm{NMR}$ and ${ }^{13} \mathrm{C}$-NMR spectra (figures
1 and 2) showed that Gsp-PS2 and Gc-PS2 have similar resonance patterns. Comparing with data reported in the literature, ${ }^{4}$ major characteristics of Gsp-PS2 and Gc-PS2 are as follows: the signal around $\delta_{\mathrm{H}} 4.51-5.12 \mathrm{ppm}$ and $\delta_{\mathrm{C}} 100.7-105.6 \mathrm{ppm}$ were assigned to anomeric protons/carbons. Among them, $\alpha$ - and $\beta$-configuration both were present, GspPS-2 consists of a mixture of $\alpha$ and $\beta$-anomers, in a proportion $1: 3(\alpha: \beta)$. For both polysaccharides, $\alpha$-glucan was the most abundant compound. Branching points at C- 6 were determined by the $-\mathrm{CH}_{2}-\mathrm{O}$ - signals at $63.7 \mathrm{ppm}$ in the spectrum, compared to the unsubstituted $-\mathrm{CH}_{2}-\mathrm{OH}$ signals at $60.5 \mathrm{ppm}$. In addition, MALDITOF mass spectrometry indicated signals in the range 40000 - $45000 \mathrm{Da}$ for Gc-PS2, and in the range 25000 - $35000 \mathrm{Da}$ for Gsp-PS2.

\section{Acute Toxicity Effects of Gsp-PS2 or Gc-PS2}

To determine any toxicity of Gsp-PS2 or Gc-PS2, by oral administration to rats at doses $50-2400 \mathrm{mg} / \mathrm{kg}$, and general symptoms and deaths were observed 14 days after administration. No animals died in the experimental time and no experimental animal demonstrated unusual clinical feature. At the $15^{\text {th }}$ day, autopsies were performed to organs of all survival animals with no specific findings observed in all experimental animals (data not shown).

\section{ANTICONVULSANT ACTIVITY}

\section{Effect of Gsp-PS2 or Gc-PS2 on Kainic acid-Induced Seizures}

The KA excitotoxicity model was stablished to induce seizures. Rats administered with $\mathrm{KA}(10 \mathrm{mg} / \mathrm{Kg})$ showed the stages 1 to 5 of seizure severity including the stage 6 (death of one animal). The first stage of neurotoxicity in rats occurred at $90 \mathrm{~min}$ after KA administration. To determine the effects of Gsp-PS2 or Gc-PS2 on KA-induced seizures, at various doses $(10,20,40,80 \mathrm{mg} / \mathrm{Kg})$ were i.p. administered 2 days before the KA injection. The pretreatment with Gsp-PS2 or Gc-PS2 in inhibiting seizures was not dose-dependent, at all doses rats only showed behavior of stage 1, after KA being administered. As mentioned before, rats exhibiting stages minor to 3 , were considered negative for seizure onset. So, Gsp-PS2 or Gc-PS2 inhibit seizures in the KA model. Rats treated only with Gsp-PS2 or Gc-PS2 at various doses (10, 20, 40, $80 \mathrm{mg} / \mathrm{kg}$ ) did not develop any symptom of stage seizure.

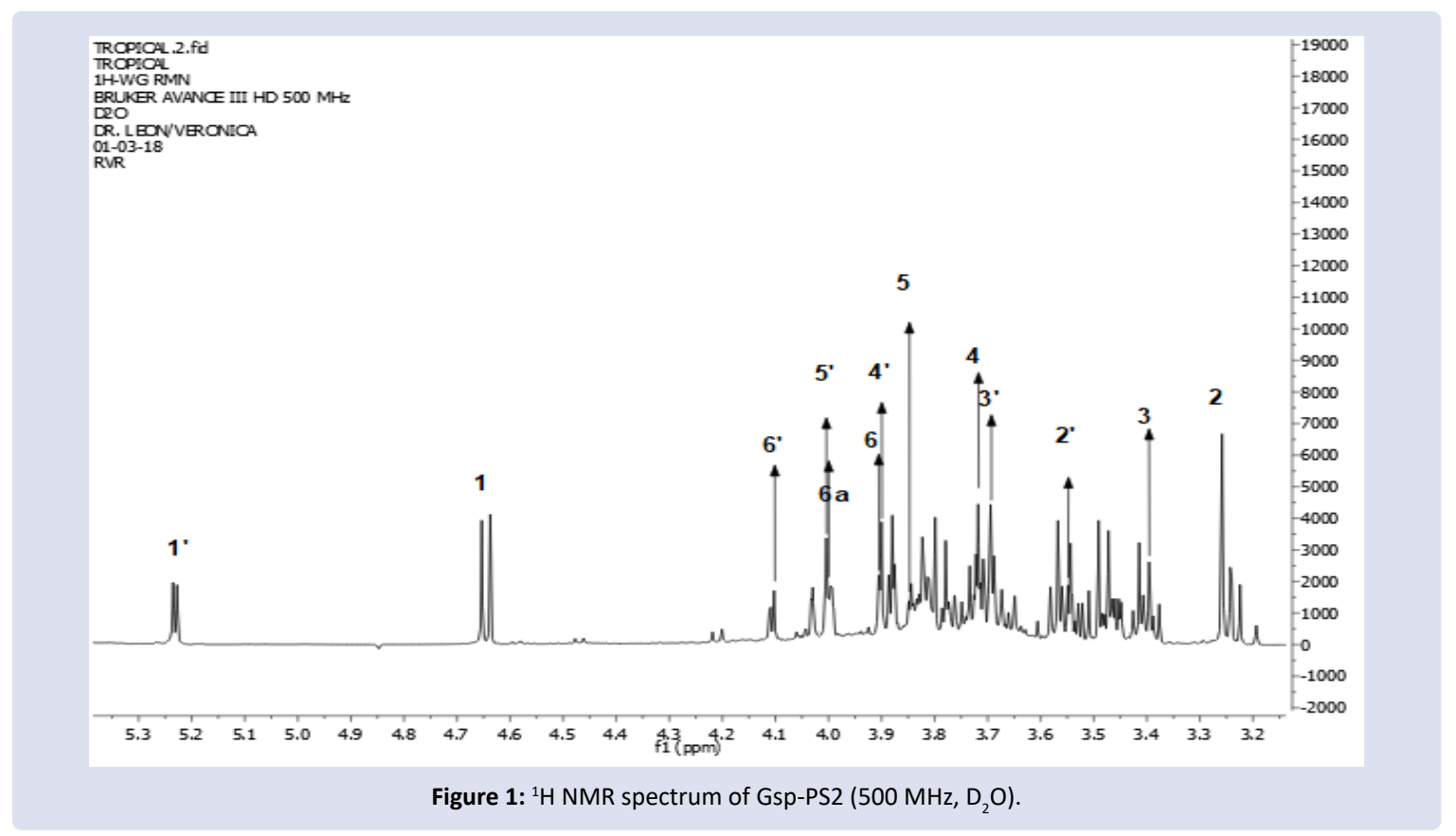




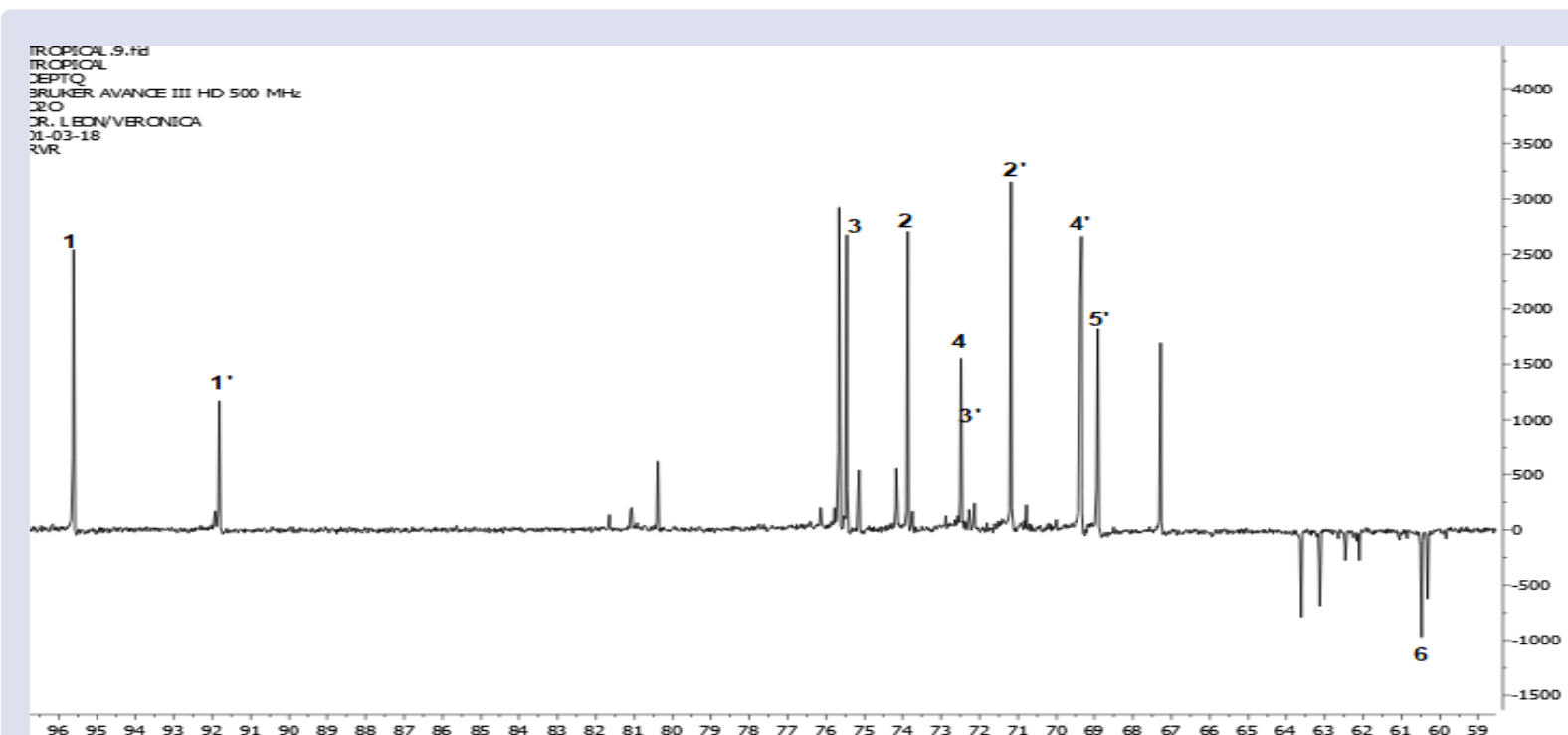

Figure 2: ${ }^{13} \mathrm{C}$ DEPTQ NMR spectrum of Gsp-PS2 (125 MHz, $\left.\mathrm{D}_{2} \mathrm{O}\right)$.

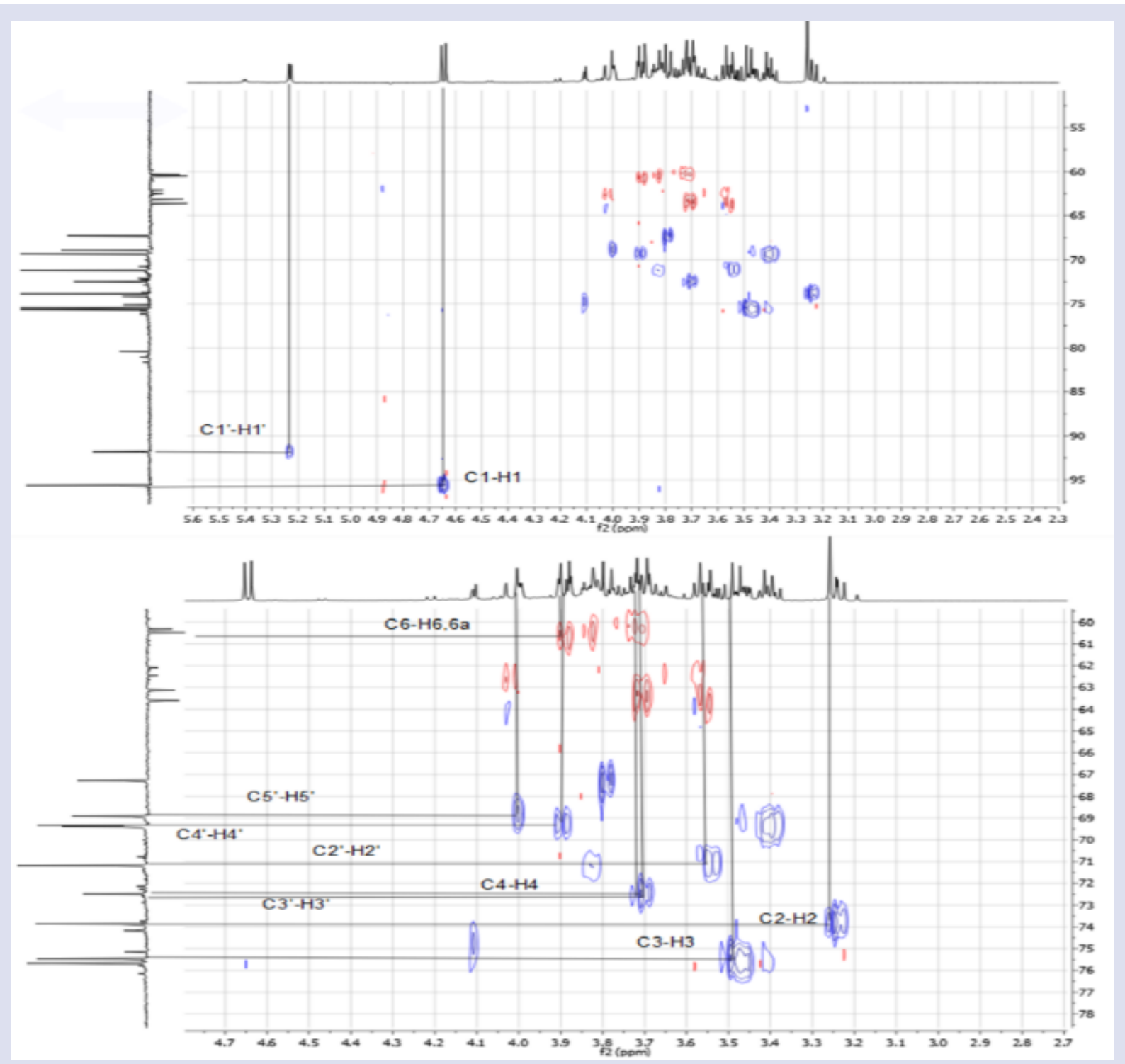

Figure 3: ${ }^{1} \mathrm{H}-{ }^{13} \mathrm{C}$ HSQC NMR spectrum of Gsp-PS2 (500 MHz, $\left.\mathrm{D}_{2} \mathrm{O}\right)$. 


\section{Effects of Gsp-PS2 or Gc-PS2 on pentylenetetrazol- induced seizures}

All animals administered $85 \mathrm{mg} / \mathrm{kg}$ of PTZ had generalized seizures. The latency to the seizure activity was $99 \pm 10 \mathrm{~s}$, and the seizure activity had a mean duration of $132 \pm 45 \mathrm{~s}$. Four of the five animals did not survive the seizures. Gsp-PS2 or Gc-PS2 was tested at doses of 10, 20, 40, and $80 \mathrm{mg} / \mathrm{kg}$. All animals pretreated with Gsp-PS2 or Gc-PS2 showed generalized seizures. The latency to seizure onset was significantly increased by all four doses of Gsp-PS2 (118 $\pm 43 \mathrm{~s}$ for $10 \mathrm{mg} / \mathrm{kg}, 133 \pm$ $50 \mathrm{~s}$ for $20 \mathrm{mg} / \mathrm{kg}, 148 \pm 61 \mathrm{~s}$ for $40 \mathrm{mg} / \mathrm{kg}$, and $160 \pm 77 \mathrm{~s}$ for $80 \mathrm{mg} /$ $\mathrm{kg}$ ). In addition, the seizure duration was significantly shortened by all doses: $10 \mathrm{mg} / \mathrm{kg}(83 \pm 15 \mathrm{~s}) 40 \mathrm{mg} / \mathrm{kg}$ dose $(21 \pm 5 \mathrm{~s})$, and a trend was seen toward a decrease in seizure duration after the $20 \mathrm{mg} / \mathrm{kg}(51 \pm 30$ s) and $80 \mathrm{mg} / \mathrm{kg}(69 \pm 37 \mathrm{~s})$ doses. Four animals (of five) pretreated with Gsp-PS2 (10 mg/kg) died, and three animals (of five) in either the 20 , 40 , or $80 \mathrm{mg} / \mathrm{kg}$ groups died. For Gc-PS2 the latency to seizure, the time of seizure, and mortality rate were similar to those observed with Gsp-PS2. The latency to onset showed the following results: $110 \pm 37 \mathrm{~s}$ for $10 \mathrm{mg} / \mathrm{kg}, 120 \pm 41 \mathrm{~s}$ for $20 \mathrm{mg} / \mathrm{kg}, 138 \pm 45 \mathrm{~s}$ for $40 \mathrm{mg} / \mathrm{kg}$, and 153 $\pm 37 \mathrm{~s}$ for $80 \mathrm{mg} / \mathrm{kg}$ ). In addition, the seizure duration was at: $10 \mathrm{mg} /$ $\mathrm{kg}(96 \pm 12 \mathrm{~s}), 27 \pm 5 \mathrm{~s}(40 \mathrm{mg} / \mathrm{kg}) ; 46 \pm 25 \mathrm{~s}(20 \mathrm{mg} / \mathrm{kg}) ;$ and $62 \pm 30 \mathrm{~s}$ $(80 \mathrm{mg} / \mathrm{kg}$ ). Four animals (of five) pretreated with Gc-PS2 $(10 \mathrm{mg} / \mathrm{kg}$ ) died, and three animals (of five) in either the $20,40 \mathrm{or} 80 \mathrm{mg} / \mathrm{kg}$ groups died (figure 4).

\section{Effects of Gsp-PS2 or Gc-PS2 on strychnine-induced seizures}

All animals administered $2 \mathrm{mg} / \mathrm{kg}$ of strychnine had generalized seizures. The latency to the seizure activity was $199 \pm 30 \mathrm{~s}$, and the seizure activity had a mean duration of $32 \pm 4 \mathrm{~s}$. All five animals did not survive the seizures. Gsp-PS2 or Gc-PS2 were tested at doses of 10, 20,40 , and $80 \mathrm{mg} / \mathrm{kg}$. All animals pretreated with Gsp-PS2 or Gc-PS2 showed generalized seizures. Gsp-PS2 or Gc-PS2 did not significantly prolong the latency to seizures induced by strychnine $(218 \pm 43 \mathrm{~s}$ for $10 \mathrm{mg} / \mathrm{kg}, 213 \pm 45 \mathrm{~s}$ for $20 \mathrm{mg} / \mathrm{kg}, 208 \pm 51 \mathrm{~s}$ for $40 \mathrm{mg} / \mathrm{kg}$, and $160 \pm$ $77 \mathrm{~s}$ for $80 \mathrm{mg} / \mathrm{kg}$ ). In addition, the seizure duration was significantly equal for all doses evaluated: $10 \mathrm{mg} / \mathrm{kg}$ dose $(28 \pm 5 \mathrm{~s}), 20 \mathrm{mg} / \mathrm{kg}(31 \pm$ $3 \mathrm{~s}), 40 \mathrm{mg} / \mathrm{kg}(31 \pm 6 \mathrm{~s}$ ), and $80 \mathrm{mg} / \mathrm{kg}(29 \pm 7 \mathrm{~s}$ ) doses (figure 5). There was no significant difference between the treatment groups Gsp-PS2 or Gc-PS2; latency to convulsions to latency to death was the same. Four animals (of five) pretreated with Gc-PS2 $(10 \mathrm{mg} / \mathrm{kg})$ died, and three animals (of five) in either the 20,40 or $80 \mathrm{mg} / \mathrm{kg}$ groups died (figure 5).

\section{Anxiolytic test}

One of the goals of this study is to determine the anxiolytic-like effects of two polysaccharide fractions from two submerged culture Ganoderma species, in laboratory animals submitted to EPM test. The EPM model is a validated and reliable test for detecting anxiolytic drug effects in rodents. The fear of height induces anxiety in the animals when they
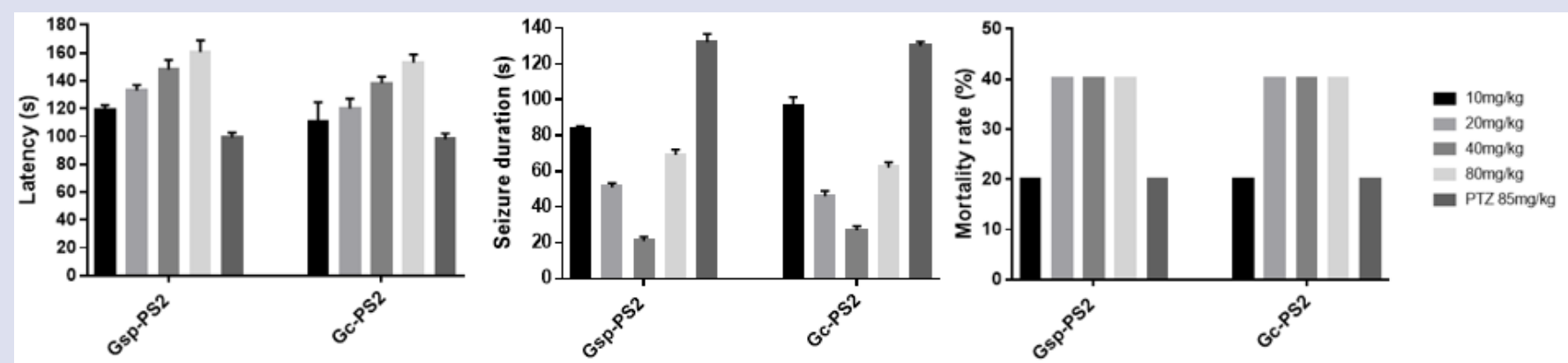

Figure 4: Effect of Gsp-PS2 on the latency seizure onset induced by pentylenetetrazol (PTZ). A: The latency to the first observable seizure activity was measured and averaged across animals in each treatment group. B: The duration of the observable seizure activity was measured for each animal and averaged across animals in each treatment group. C: The mortality rate in each treatment group is presented.
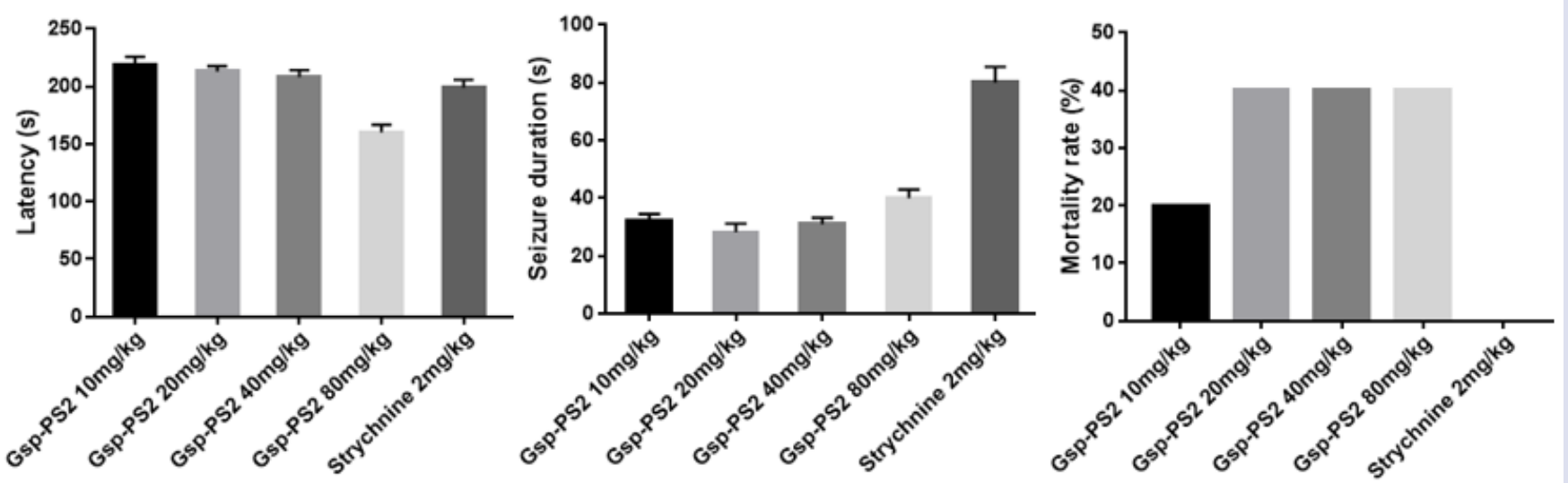

Figure 5: Effect of Gsp-PS2 on the seizures induced by strychnine A: The latency to the first observable seizure activity was measured and averaged across animals in each treatment group. B: The duration of the observable seizure activity was measured for each animal and averaged across animals in each treatment group. C: The mortality rate in each treatment group is presented. 


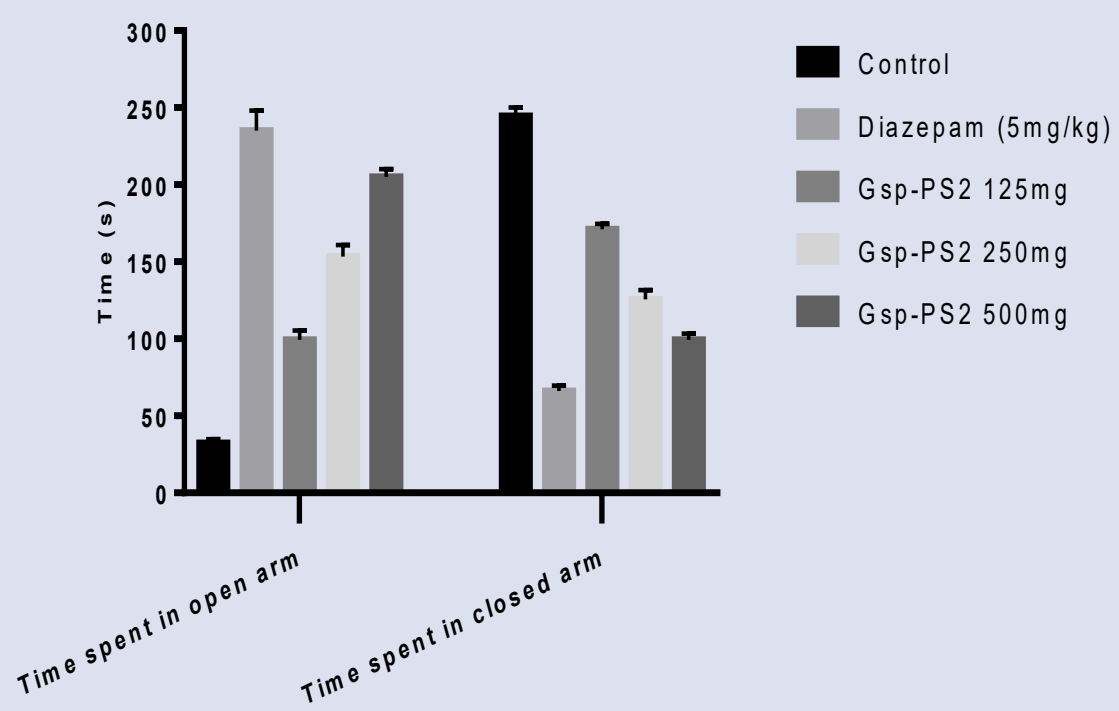

Figure 6: Effects of Gsp-PS2 or Gc-PS2, or diazepam on time spent by mice in open arms in elevated plus maze model. Data expressed as mean $\pm \mathrm{SEM}, \mathrm{n}=4 . * * \mathrm{P}<0.01, * * * \mathrm{P}<0.001$ vs. saline group, one-way ANOVA with post hoc Tukey test.

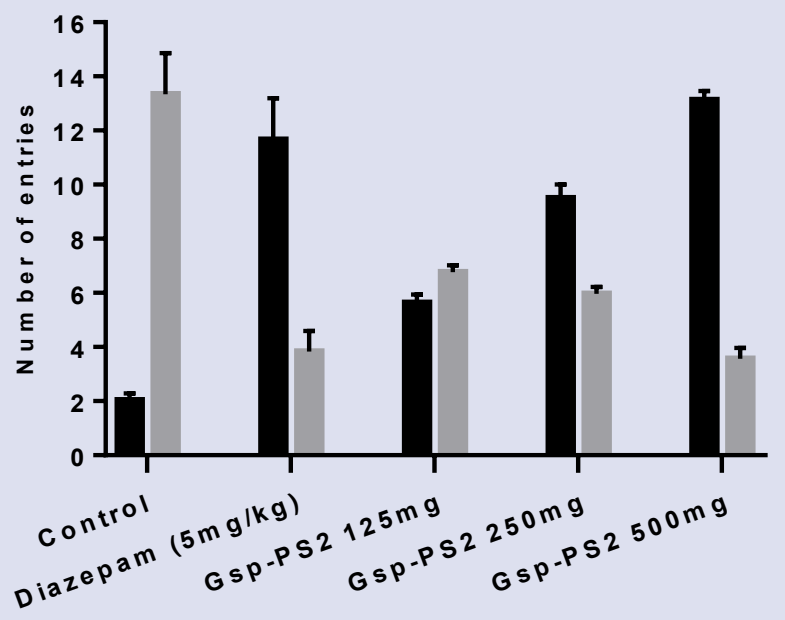

Open arm entry

Closed arm entry

Figure 7: Effects of Gsp-PS2 or Gc-PS2, or diazepam on the number of entries by mice in open arms in elevated plus maze model. Data expressed as mean $\pm \mathrm{SEM}, \mathrm{n}=4 . * * \mathrm{P}<0.01, * * * \mathrm{P}<0.001$ vs. saline group, one-way ANOVA with post hoc Tukey test.
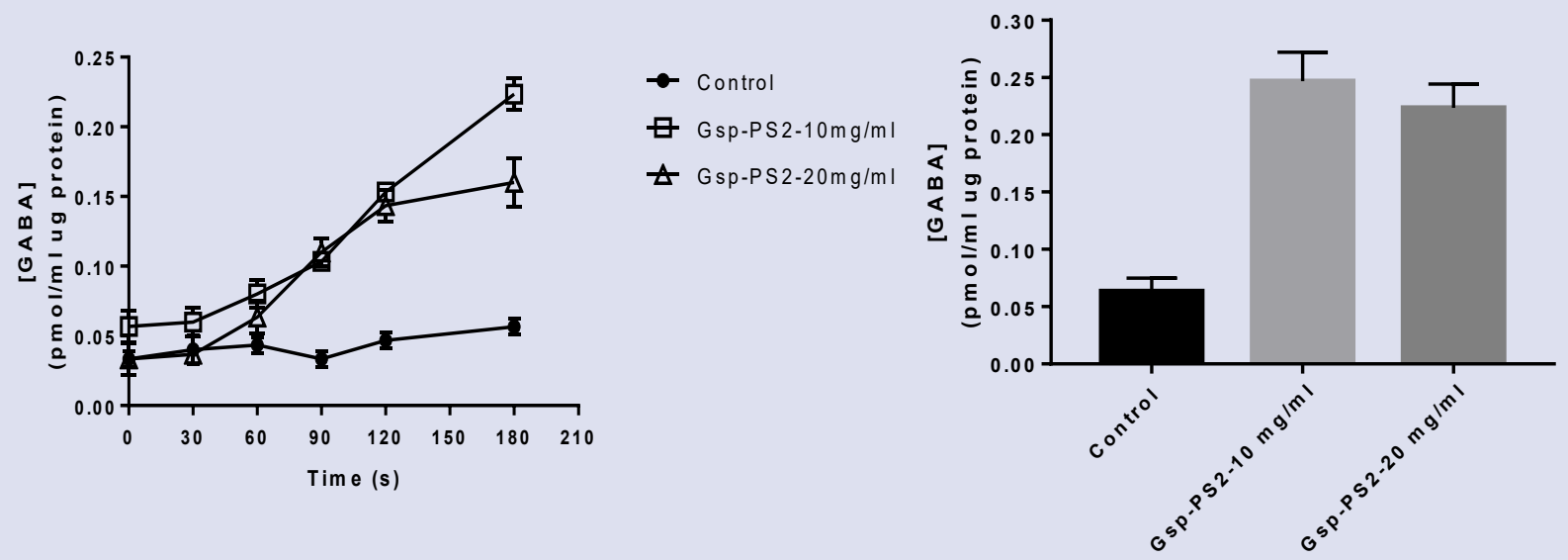

Figure 8: Release of endogenous GABA in cerebral cortex slices evoked by Gsp-PS2 at $10 \mu \mathrm{g} / \mathrm{mL}, \mathrm{Gsp}-\mathrm{PS} 2 \mathrm{at} 20 \mu \mathrm{g} / \mathrm{mL}$, and control group. Values are means \pm SEM of 5 independent experiments. 
are placed on the EPM apparatus. Administration of Gsp-PS2 or GcPS2 $(125-500 \mathrm{mg} / \mathrm{kg})$ to the animals caused a significant increase in the number of entries and the average time spent in the open arms of the EPM (figure 6). These results were comparable with the effects produced by the group that received diazepam.

\section{Effects of Gsp-PS2 or Gc-PS2 on Locomotor Activity}

The effect of Gsp-PS2 on locomotor activity showed a mean activity count in the control group of $2762 \pm 195$, and $2542 \pm 169$ tested at doses of 250 or $500 \mathrm{mg} / \mathrm{kg}$, respectively. However, the changes in spontaneous locomotor activity were not statistically significant 2514 \pm 201 compared with control group. Similar results were obtained for Gc-PS2.

\section{Effect of Gc-PS2 or Gsp-PS2 on endogenous GABA release}

Gsp-PS2 or Gc-PS2 increased significantly the release of GABA, showing both of them a similar behavior, with a maximum effect between 120 and $210 \mathrm{~s}$ (figure 8). The maximum values obtained were: $0.18 \mathrm{pmol} / \mu \mathrm{g}$ and $0.21 \mathrm{pmol} / \mu \mathrm{g}$ of protein (Gc-PS2 10 and $20 \mu \mathrm{g} / \mathrm{mL}$ ), 0.25 and $0.22 \mathrm{pmol} / \mu \mathrm{g}$ of protein (Gsp-PS2 10 and $20 \mu \mathrm{g} / \mathrm{mL}$ ).

\section{Immunohistochemistry assays}

From the behavioral results, we decided to evaluate the efficacy of Gsp-PS2 or Gc-PS2 as a neuroprotector factor against KA-induced neurodegeneration. We studied hippocampal and cortex sections of rats from all groups stained with hematoxylin and eosin (HE) to detect degenerated neurons (figure 9). We can observe that in control group there was no evidence of neuronal damage. A preservation of cortex neurons was found in rats treated with Gsp-PS2 or Gc-PS2 (10 mg/ $\mathrm{kg}$ ). The neurons majority in cortex sections in the group treated with $\mathrm{KA}(10 \mathrm{mg} / \mathrm{Kg})$, appeared shrunken with eosinophilic cytoplasm, triangulated pyknotic nuclei, and edema. In contrast, rats pre-treated with Gsp-PS2 or Gc-PS2 (10 mg/Kg) did not show a significant decrease in the number of neurons after KA injection.

Brain sections were also analyzed to determine the effect of these treatments on astrocyte activation. Rats treated only with Gsp-PS2 or Gc-PS2 $(10 \mathrm{mg} / \mathrm{Kg})$ displayed a staining for GFAP very similar to that of the control group, and astrocytes showing few morphological changes. Reactive astrocytes with increased GFAP labeling and altered morphology in hippocampus and cortex sections were observed in animals that received KA injection. Finally, animals pretreated with Gsp-PS2 or Gc-PS2 $(10 \mathrm{mg} / \mathrm{Kg})$ before the insult with KA displayed less staining for GFAP and activated astrocytes than KA group (figure 10). Pretreatment with Gsp-PS2 or Gc-PS2 inhibited astrocyte activation. In figure 10 we can also observe that there are significant differences in cell damage, between different treatments.

NeuN labeling was used to encompass neuronal cell losses by staining for detecting neurons in the process of degeneration. After KA injection, the numbers of NeuN-positive cells in cortex sections were significantly decreased. Also, a significative loss of cells, interstitial edema and cellular damage was observed in the cortex. Group pretreated with Gsp-PS2 showed a similar expression of NeuN-positive neurons to control group (figure 11).

\section{DISCUSSION}

Studies on Ganoderma species have been performed mainly on Asian and European strains, but few studies have considered Mexican strains. ${ }^{4,59}$ Moreover, Ganoderma mushrooms from deciduous forest have been few studied. ${ }^{10}$

Several biologically active metabolites have been isolated from G. lucidum fruiting body, however, their harvest time is long, the metabolite yields are usually low, and the ecological niche and contaminating microorganisms may alter the chemical components. Traditional production of G. lucidum fruiting bodies in solid cultures has similar disadvantages than harvesting wild mushrooms. ${ }^{11}$ The submerged mycelial cultivation, has become an alternative method for efficient production of fungal biomass and valuable metabolites in a short period of time with more reproducible results. ${ }^{12}$

Isolation of mixtures of a- and $\beta$-glucan from submerged culture of mycelium, is less frequent than isolation of $\beta$-glucans from fruiting bodies of mushrooms. ${ }^{13}$ To our best knowledge, this is the first report of isolation of a mixture of $\alpha$ - and $\beta$-glucan (Gsp-PS2) from a submerged culture of a Ganoderma species collected in a deciduous forest in Mexico. Although Gsp-PS2 is composed of glucose units as Gc-PS2, molecular weight is different, and besides the relative proportions of $\alpha$ - and $\beta$-glucan are also different to those reported for G. lucidum. ${ }^{4}$
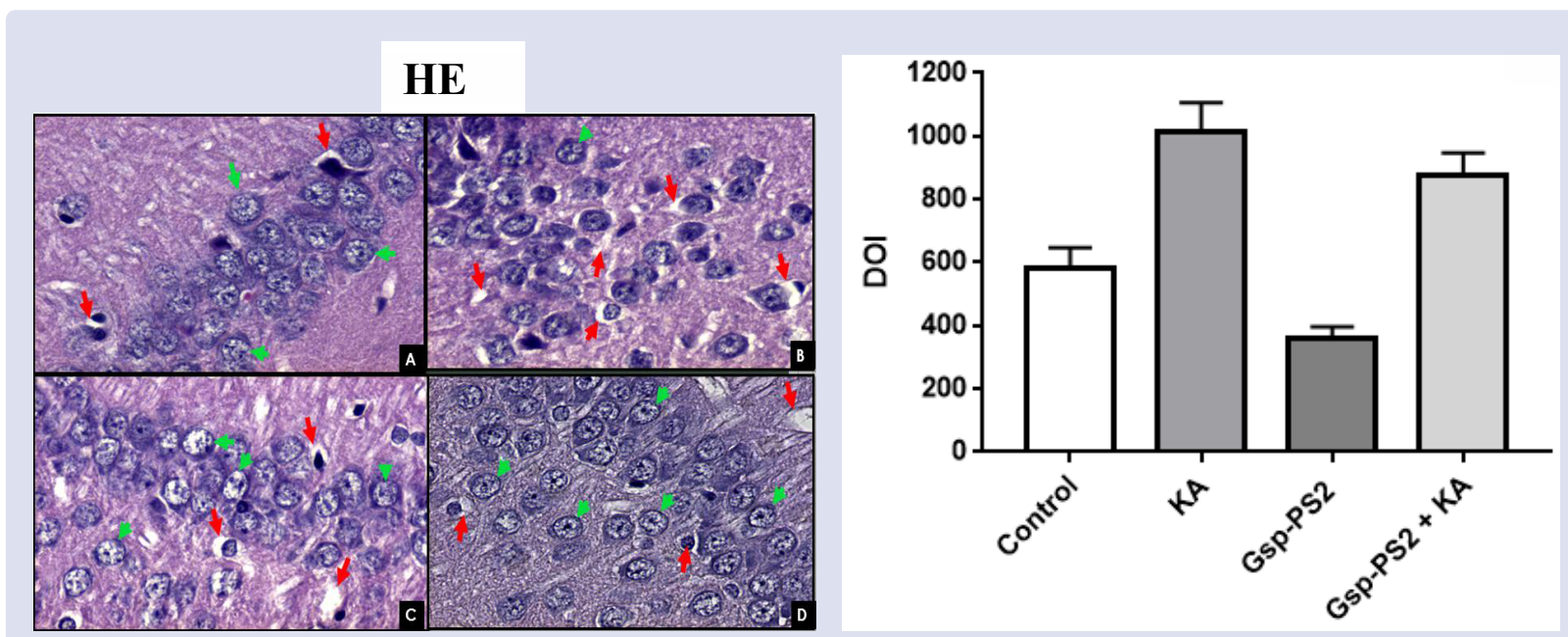

Figure 9: Photomicrographs of tissue from CA1 section of hippocampus, stained with HE. A) Control Group; C) Group treated with Ganoderma sp. shows little interstitial edema (red arrows) and a large number of healthy neurons (green arrows); B) Group treated with kainic acid, a significant increase in interstitial edema is observed (red arrows), and little presence of healthy cells (green arrows); D) Group treated with Ganoderma sp. and (two days after) kainic acid, shows a significant decrease in interstitial edema (red arrows) and a high number of functional neurons (green arrows). 


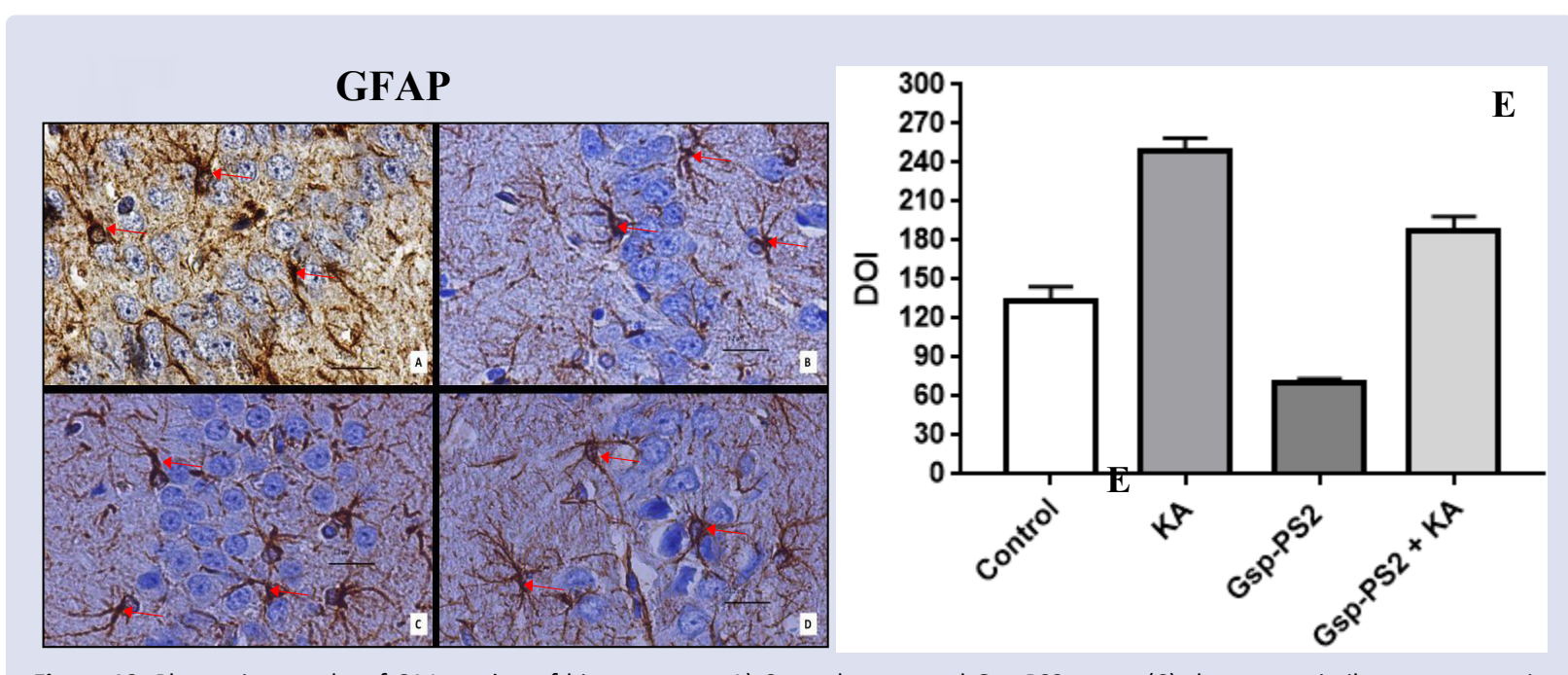

Figure 10: Photomicrographs of CA1 section of hippocampus: A) Control group and Gsp-PS2 group (C) show very similar appearance in normal cells (white arrow) and slight expression of GFAP; B) Group treated with KA shows large number of reactive astrocytes (black arrow), nucleosomatic retraction cell (black circle), and high GFAP expression; D) Group pretreated with Gsp-PS2 (+ KA) reduced reactive astrocytes and GFAP expression.

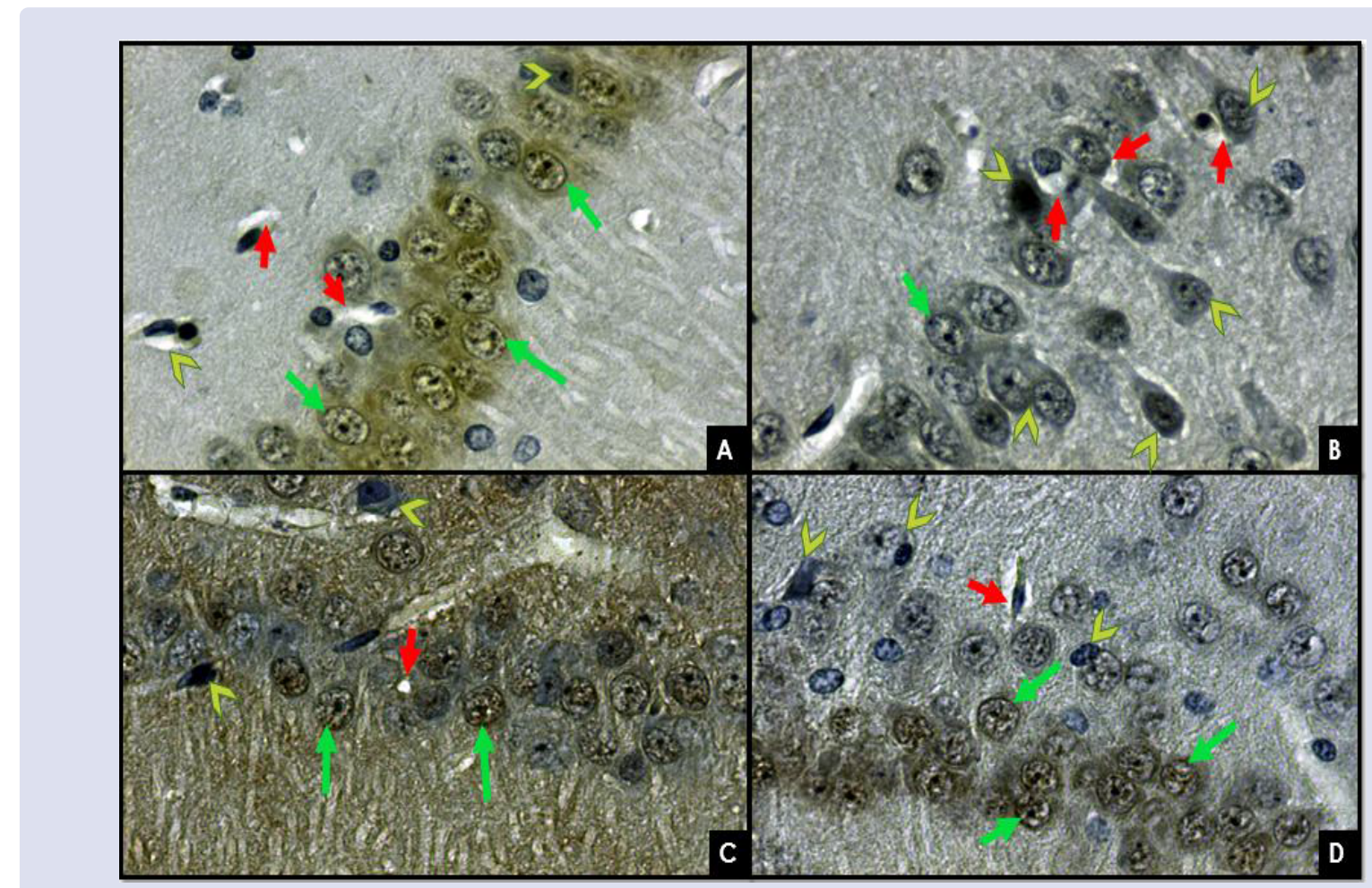

Figure 11: Photomicrographs of CA1 section of hippocampus: A) Control group and Gsp-PS2 group (B) show very similar appearance in normal cells (white arrow) and slight expression of NeuN; C) Group treated with KA shows large amount of nucleosomatic retraction cell, and high NeuN expression; D) Group pretreated with Gsp-PS2 (+ KA) reduced NeuN expression.

Oral administration of Gc-PS2 or Gsp-PS2 did not result in abnormal changes in behavioral signs, mortality or autopsy findings in experimental rats. Therefore, under this acute oral toxicity experiment condition, the median lethal dose (LD50) of Gc-PS2 or Gsp-PS2 was determined to be higher than $2000 \mathrm{mg} / \mathrm{kg}$. Based on OECD (2002) test guidelines, Gc-PS2 or Gsp-PS2 was considered nontoxic owing to the absence of deaths at a dose of $2000 \mathrm{mg} / \mathrm{kg}$, thus suggesting the nontoxicity of Gc-PS2 or Gsp-PS2.

This study compared the anticonvulsant effects of Gsp-PS2 with three different convulsant chemicals. The possibility that Gsp-PS2 may have anticonvulsant activity was suggested by our published results obtained with other two Ganoderma species collected in Mexican forests. ${ }^{4,5}$ In this study, the partially purified polysaccharide fraction (Gsp-PS2) showed anticonvulsant activity in the KA model, whereas Gsp-PS2 exhibited little effect on the seizures produced by PTZ or strychnine models. This suggests that the effect of Gsp-PS2 is to slow or block synchronization, or speed of spread of focal epileptiform activity. This is supported by the observation that Gsp-PS2 could completely inhibit seizures induced by KA, but not those induced by strychnine or PTZ. The seizures induced by KA begin slowly with hippocampal/limbic 
system seizures with a latency to the first wet-dog shake (a limbic seizure) of $90 \mathrm{~min}$. These seizures then gradually spread to the cortex and other brain areas. ${ }^{14}$ In contrast, the seizures induced by strychnine, which are also partial seizures with secondary generalization, have a latency of less than 4 min to the first forelimb clonus (a cortical seizure). PTZ induces generalized seizures with a latency of $2 \mathrm{~min}$. The differential effect of Gsp-PS2 in the different models also could due to that Gsp-PS2 being more effective in the limbic system compared with the cortex. The exact mechanism by which polysaccharides produce the anticonvulsant action remains to be determined.

The protective activity induced by GspPS-2 to resist KA induced seizures is similar to those reported by us with an oligosaccharide fraction isolated from a Ganoderma lucidum strain and with a polysaccharide fraction isolated from a Ganoderma curtissi strain, both collected in Mexican forests. ${ }^{4,5}$ In a study evaluating the anticonvulsant activity of a Ganoderma lucidum aqueous extract, it was reported no alteration in seizure threshold for the onset of generalized clonus in the PTZ test, and also failed to increase the threshold for the onset of forelimb tonus in the i.v. PTZ test and the threshold for hindlimb extension in the MEST test, ${ }^{7}$ showing similar results with ours but did not mention the chemical content of the aqueous extract from mycelium used in their study, meanwhile in our study we have shown that polysaccharides are the principal constituents in the fraction administered to rats. In a similar sense, Aguirre-Moreno et al. ${ }^{4}$ and León-Rivera et al. ${ }^{5}$ also determined the anticonvulsant activity of polysaccharides isolated from the broth of submerged cultures of Ganoderma species. Although, oral administration is the most common used by humans (as tablets, capsules, or liquid extracts), bioavailability is lower for drugs administered orally than for drugs injected intraperitoneally. These results suggest the potential anticonvulsant activity of Gsp-PS2.

Imbalance between excitatory and inhibitory neurotransmitter in the brain is a cause contributing to seizure development. Gamma aminobutyric acid (GABA) is the major inhibitory neurotransmitter in the central nervous system (CNS). GABA function impairment is documented to provoke seizures, whereas facilitation has an anticonvulsant effect. GABA is synthesized exclusively in GABAergic neurons, from glutamate in the presence of enzyme glutamic acid decarboxylase. Upon synaptic release, GABA acts on three specific receptors, inotropic $\mathrm{GABA}_{\mathrm{A}}$, metabotropic $\mathrm{GABA}_{\mathrm{B}}$ and the newly characterized $\mathrm{GABA}_{\mathrm{C}}{ }^{15}$

It has been reported that phenobarbitone and diazepam have shown antiepileptic effects by enhancing the GABA-mediated inhibition in the brain. ${ }^{16}$ It is possible that diazepam and GC-PS2 or Gsp-PS2 antagonize pentylenetetrazole convulsion in this study by enhancing GABA neurotransmission. Since Gc-PS2 or Gs-PS2 delayed the onset of pentylenetetrazole-induced convulsion, it is probable that they may be interfering with GABA aminergic mechanism(s) to exert its anticonvulsant effect. Besides, inhibition of the KA-induced convulsion by Gc-PS2 or Gsp-PS2, and activity against generalized tonic-clonic and cortical focal seizures suggests that Ganoderma polysaccharides (Gc-PS2 or Gsp-PS2) are useful in suppressing generalized tonic-clonic seizures by regulating GABA mediated synaptic inhibition. Since PTZ is a GABA $A_{A}$ receptor antagonist, Gc-PS2 or Gsp-PS2 may be acting by increasing $\mathrm{GABA}$ concentration in the brain.

We also aimed to evaluate the acute anxiolytic-like effect of Gc-PS2 or Gsp-PS2 polysacharides in mice during the elevated plus maze test. Our results showed a significant anxiolytic-like activity of both polysaccharides. Our results are consistent with findings of Matsuzaki et al., ${ }^{17}$ who observed an anxiolytic-like effect of an extract from culture medium of G. lucidum mycelium in rats using the same test.

Acute treatment with Gc-PS2 or Gsp-PS2 did not cause locomotor deficit or sedation. No changes in activity counts after acute treatment with Gc-PS2 or Gsp-PS2 is in accordance with previous reports after administration of a single dose of a G. lucidum extract. ${ }^{2,7}$

Polysaccharides from G. lucidum protected rat cerebral cortical neurons against injury induced by hypoxia/reoxygenation exposure, ${ }^{18}$ as well as reduced neurological deficits in rats after cerebral ischemic injury. $G$. lucidum extract protected dopaminergic neurons from degeneration. ${ }^{19}$ Altogether, G. lucidum has been postulated as a novel therapeutic approach in the prevention and treatment of neurodegenerative diseases. ${ }^{20}$ The administration of KA caused hippocampal and cortex neuronal death. Pretreatment with Gsp-PS2 protected the hippocampus and cortex neurons against KA-induced excitotoxicity. These results are similar to those reported with a polysaccharide fraction of Ganoderma curtisii, ${ }^{5}$ indicating the beneficial properties of polysaccharides from Ganoderma strains collected in Mexico.

Immunohistochemistry evidenced neuronal death, some dystrophic neurites and pyramidal cell disarray promoted by KA compared with control group. Also, we found a moderate decrease of NeuN positive cells in groups pretreated with Gsp-PS2. Neuronal loss was less evident in group pretreated with Gsp-PS2 $(80 \mathrm{mg} / \mathrm{kg})$ in agreement with an increase of NeuN positive cells. So, we decided to identify the presence of mature neurons with an anti-NeuN antibody, microglial cells, and an anti-glial fibrillary acidic protein (GFAP) antibody to detect astrocytes. KA promotes an increase of GFAP, while NeuN cells showed a slight reduction compared with control group (Figure 11). These morphological changes are signs of glial activation. Previous studies have shown that the administration of Ganoderma lucidum extracts (containing polysaccharides) exert neuroprotective effects. ${ }^{4,5,19}$ The results obtained by us show for first time that submerged culture of a Ganoderma species from a Mexican deciduous forest produces polysaccharide with neuroprotective activity on rats subjected to kainic acid-seizure induction. The results of this study also demonstrate that pretreatment with Gsp-PS2 inhibit microglial activation in KA-treated hippocampus and cortex of rats, resulting in a decrease level of GFAP expression.

Previous report has shown the immunomodulatory and neuroprotective activity of polysaccharides isolated from submerged culture of Ganoderma species. ${ }^{21}$ Our results indicate that Gsp-PS2 may prevent seizures and seizure-induced brain damage associated with inflammatory responses. ${ }^{4.5}$ The anticonvulsant effect of Gsp-PS2 can be also mediated through stimulation of GABAergic neurotransmission; mushroom compounds have been suggested to act, at least in part, as benzodiazepine receptor agonists. ${ }^{22}$

In mature brain, microglia typically exist in a resting state characterized by ramified morphology and monitors the brain environment. In response to abnormal stimuli, such as environment toxins, neurotoxins, microglia become activated and can induce significant and highly detrimental neurotoxic effects by the excess production of a large array of cytotoxic factors such as nitric oxide. Gsp-PS2 polysaccharides also reduced nitric oxide (NO) production, and this disruption of $\mathrm{NO}$ transmission can explain anticonvulsant effect. ${ }^{23}$

Polysaccharides from G. curtisii or Ganoderma sp. have shown a diminishing on neuronal NO synthase, similar to the results reported by G. lucidum. ${ }^{23}$ Although, disruptions of NO transmission by NO synthase inhibitors can exert pro- and anticonvulsant effects or no effects on seizure activity. So, the results obtained by us and those reported are suggesting that a reduction in NO production is involved in the anticonvulsant activity.

\section{CONCLUSION}

Polysaccharides isolated from submerged culture of Ganoderma sp. or Ganoderma curtisii with similar chemical composition afforded anticonvulsant activity mediated through stimulation of GABAergic 
neurotransmission and by disruption of neuronal NO transmission. Besides, both polysaccharides exhibited neuroprotective effects by diminishing neuronal damage and glial activation. Further studies are necessary to elucidate the anticonvulsant mechanism of these $\alpha$-, $\beta$-glucans.

\section{FUNDING}

Nil.

\section{ACKNOWLEDGMENTS}

Authors are grateful to LANEM (CIQ, UAEM) for use of laboratory facilities. We thank Dra. Blanca Eda (CIQ, UAEM) for the recording of NMR spectra. V. Núñez is grateful to CONACYT for scholarship 572999 .

\section{CONFLICTS OF INTEREST}

There are not conflicts of interest.

\section{REFERENCES}

1. Mintzer S, Yi M, Hegarty S, Maio V, Keith S. Hyperlipidemia in patients newly treated with anticonvulsants: A population study. Epilepsia. 2020;61(2):259-266

2. Chu QP,Wang LE, Cui XY, Fu HZ, Lin ZB, Lin SQ, et al. Extract of Ganoderma lucidum potentiates pentobarbital-induced sleep via a GABAergic mechanism. Pharmacol. Biochem. Behav. 2007;86(4):693-698

3. Zhang R, Xu S, Cai Y, Zhou M, Zuo X, Chan P. Ganoderma lucidum protects dopaminergic neuron degeneration through inhibition of microglial activation. Evid. Based Complement. Alternat. Med. 2011;2011:156810.

4. Aguirre Moreno A, Villeda Hernandez J, Campos Peña V, Herrera Ruiz M, Montiel Arcos E, Tello I, e al. Anticonvulsant and Neuroprotective Effects of Oligosaccharides from Lingzhi or Reishi Medicinal Mushroom, Ganoderma lucidum (Higher Basidiomycetes). Int. J. Med. Mushrooms. 2013;15(6):555-568.

5. León-Rivera I, Villeda-Hernandez J, Montiel-Arcos E, Tello I, Rios MY, Estada-Soto S, Aguilar AB, Núñez-Urquiza $V$, Méndez-Mirón $\mathrm{J}$, Campos-Peña V, Hidalgo-Figueroa S, Hernández E, Hurtado G.. Neuroprotective Effects of Ganoderma curtisii Polysaccharides After Kainic Acid-Seizure Induced. Pharmacognosy J. 2019;11(5):1046-1054.

6. Banothu V, Neelagiri C, Adepally U, Lingam J, Bommareddy K. Phytochemical screening and evaluation of in vitro antioxidant and antimicrobial activities of the indigenous medicinal plant Albizia odoratissima. Pharm. Biol. 2017;55(1):1155-1161.

7. Socala K, Nieoczym D, Grzywnowicz K, Stefaniuk D. Wlaz P. Evaluation of anticonvulsant, antidepressant-, and anxiolyticlike effects of an aqueous extract from cultured mycelia of the Lingzhi or Reishi medicinal mushroom Ganoderma lucidum (Higher Basidiomycetes) in mice. Int. J. Med. Mushrooms. 2015;17(3):209-218.

8. Castro-García JM, León-Rivera I, Gutiérrez MC. Resin glycosides evoke the Gaba release by sodium- and/or calcium-dependent mechanism. Biomedicine \& Pharmacotherapy. 2018;97:496-502.

9. Meneses ME, Martínez Carrera D, Torres N, Sánchez Tapia M, Aguilar López M, Morales P, et al. Hypocholesterolemic Properties and Prebiotic Effects of Mexican Ganoderma lucidum in C57BL/6 Mice. PLoSONE. 2016;11(7): e0159631.
10. Tripathy S, Gupta N. A Study on Genus Ganoderma from Deciduous Forests of Odisha, India. J Bacteriol Mycol Open Access. 2015;1(2):28-33.

11. Gao JJ, Nakamura N, Min BS, Hirakawa A, Zuo F, Hattori M. Quantitative Determination of Bitter Principles in Specimens of Ganoderma lucidum Using High-Performance Liquid Chromatography and Its Application to the Evaluation of Ganoderma Products. Chem. Pharmaceut. Bull. 2004;52(6):688-695

12. Simonic J, Stajic M, Glamoclija J, Vukojević J, Duletic Lausevic $\mathrm{S}$, Brceski I. Optimization of submerged cultivation conditions for extra- and intracellular polysaccharide production by medicinal Ling Zhi or Reishi mushroom Ganoderma lucidum (W. Curt.: Fr.) P. Karst. (Aphyllophoromycetideae). Int. J. Med. Mushrooms. 2008;10(4):351-360

13. Habijanic J, Berovic M, Boh B, Plankl M, Wraber B. Submerged cultivation of Ganoderma lucidum and the effects of its polysaccharides on the production of human cytokines TNF- $\alpha$, IL-12, IFN-y, IL-2, IL-4, IL-10 and IL-17. New Biotechnology 2015;32(1):85-95.

14. Lothman EW, Collins RC. Kainic acid induced limbic seizures: metabolic, behavioral, electroencephalographic and neuropathological correlates. Brain Res. 1981;218(1):299-318.

15. Plech T, Kaproń B, Łuszczki JJ, Wujec M, Paneth A, Siwek A, Kołaczkowski M, Żołnierek M, Nowak G. Studies on the anticonvulsant activity and influence on GABA-ergic neurotransmission of 1,2,4-triazole-3-thione based compounds. Molecules 2014;19:11279-11299.

16. Abbas Zaidi SM, Pathan SA, Singh S, Jamil S, Ahmad FJ, Khar RK. Anticonvulsant, anxiolytic and neurotoxicity profile of Aqarqarha (Anacyclus pyrethrum) DC (Compositae) root ethanolic extract. Pharmacology \& Pharmacy 2013;4:535-541.

17. Matsuzaki H, Shimizu Y, Iwata N, Kamiuchi S, Suzuki F, lizuka H, Hibino Y, Okazaki M. Antidepressant-like effects of a water-soluble extract from the culture medium of Ganoderma lucidum mycelia in rats. BMC Complement. Altern. Med. 2013;13:370-373.

18. Zhao HB, Lin SQ, Liu JH, Lin ZB. Polysaccharide Extract Isolated From Ganoderma lucidum Protects Rat Cerebral Cortical Neurons From Hypoxia/Reoxygenation Injury. J. Pharmacol. Sci. 2004;95(2):294-298.

19. Zhou ZY, Tang YP, Xiang J, Wua P, Jin HM, Wang Z, et al. Neuroprotective effects of water-soluble Ganoderma lucidum polysaccharides on cerebral ischemic injury in rats. J. Ethnopharmacol. 2010;131(1):154-164.

20. Zhao C, Zhang C, Xing Z, Ahmad Z, Li JS, Chang MW Pharmacological effects of natural Ganoderma and its extracts on neurological diseases: A comprehensive review. Int J. Biological Macromolecules. 2019;121:1160-1178.

21. Bao X, Liu C, Fang J, Li X. Structural and immunological studies of a major polysaccharide from spores of Ganoderma lucidum (Fr.) Karst. Carbohyd. Res. 2001;332(1):67-74.

22. Akkol EK, Ilhan M, Karpuz B, Genç Y, Sobarzo-Sánchez E. Sedative and Anxiolytic Activities of Opuntia ficus indica (L.) Mill.: An experimental assessment in mice. Molecules 2020;25:184.

23. Tung NT, Cuong TD, Hung TM, Lee JH, Woo MH, Choi JS, et al. Inhibitory effect on NO production of triterpenes from the fruiting bodies of Ganoderma lucidum. Bioorg. Med. Chem. Lett. 2013;23(5):1428-1432 


\section{GRAPHICAL ABSTRACT}
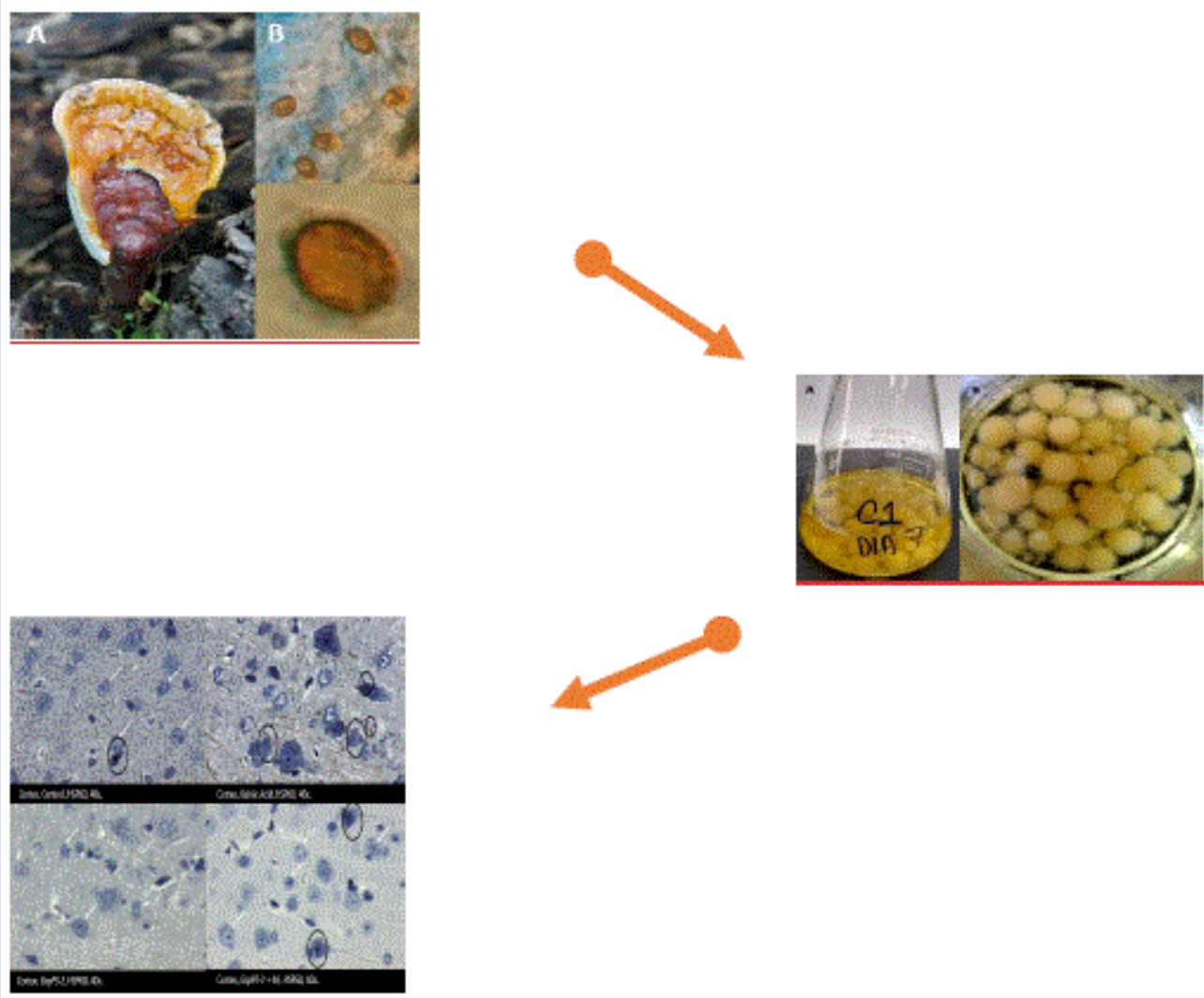

\section{ABOUT AUTHORS}

M. Sc. Verónica Nuñez Urquiza studied the Bachelor on Industrial Chemistry at Facultad de Ciencias Químicas e Ingeniería, Universidad Autónoma del Estado de Morelos (UAEM) with a thesis about chemistry of glycolipids. Later she obtained the degree of Master in Sciences (Chemistry) at UAEM developing a methodology for the production of polysaccharides from submerged culture of Ganoderma lucidum mycelium, The present article contains part of the results of her PhD Thesis at UAEM.

Dra. Juana Villeda Hernández (1957 - 2018) studied her Bachelor and M. Sc. degree at Facultad de Ciencias, Universidad Nacional Autónoma de México (UNAM). She got the PhD degree at Universidad Autónoma Metropolitana (Unidad Iztapalapa) performing studies with exotoxicity on rat brain. She was a Researcher at Instituto Nacional de Neurología y Neurocirugía, developing the study of neurodegenerative diseases.

M. Biol. Sc. ELIZUR MONTIEL ARCOS completed his Bachelor studies at Escuela de Ciencias Biológicas (UAEM), a Master's degree in Biology at the Facultad de Ciencias, UNAM. He was a member Organizer of Second National Congress of Mycology, Morelos, Mexico. Cocherman of the Eighth International Congress, Biology of fungi and their products, Morelos, Mexico. Active member of the Mexican Society of Mycology (CONACyT). He was responsible of Project "Fungi del Corredor Biológico Chichinautzin". Author of: 8 articles in Mycology Mexican Journals de Micología, 7 Articles in indexed journals, 8 book chapters and a fungi recipe book.

Dr. Isaac Tello Salgado studied his Bachelor at Facultad de Ciencias Biológicas, UAEM. He received the PhD degree at Colegio de Posgraduados, Puebla, México, performing the molecular study of several strains of mushrooms collected in Mexico as his theme of Thesis. He is currently a Researcher in the Mycology Laboratory, Centro de Investigaciones Biológicas, UAEM. His research is focused in the study and business of medicinal mushrooms.

Dra. Victoria Campos Peña studied her Bachelor in Experimental Biology, at Universidad Autónoma Metropolitana (Unidad Iztapalapa). She got the M. Sc. (Molecular Biomedicine) and PhD degrees at Centro de Investigación y Estudios Avanzados performing studies with the neuropathology of Alzheimer. She did a Research stay at Northwestern University Medical School in 2000. Currently she is a Researcher at Instituto Nacional de Neurología y Neurocirugía, developing the study of neurodegenerative diseases. 
Dra. Maribel Lucila Herrera Ruiz is Researcher at Centro de Investigación Biomédica del Sur, IMSS focused on the research on the pharmacological evaluation of natural products, mainly derived from medicinal plants, in the areas of anxiety, depression, neuroinflammation and cerebral vascular damage. In addition to the interaction between isolated molecules (terpenes, flavonoids, coumarins, etc.) and with synthetic drugs whose mechanism of action is already known. She works also, with models of vascular damage associated with obesity and hypertension.

Dra. María del Carmen Gutiérrez is Profesor Researcher at Centro de Investigación en Biotecnología, UAEM. The projects she has been working on includes the study of the different components of the venom of species of Scolopendra, emphasizing those that have an effect on the nervous system, specifically, on the mechanisms of neurotransmission in both mammals and mammals. arthropods. Similarly, we are looking for peptides with antimicrobial activity that could be contained in centipede venom. And besides, neuro-pharmacological evaluation studies of medicinal plant extracts with biotechnological, with emphasis on the pre- and post-synaptic mechanisms of neurotransmission.

Dra. Vera Petricevich got her PhD degree at Universidad Sao Paulo, Brasil. She is Profesor Researcher at Facultad de Medicina, UAEM. Her research studies focus on the effects of extracts of plant origin and poisons of animal origin on the mechanisms of the Response Immune and the consequences of these on the health of animals experimental. In particular, on the response inflammatory and its impact on the development of the immune response, some types of bacterial and viral infections and chronic inflammation, in addition to its role in the development of pathologies. A particular interest is the study of the mechanisms of molecular toxicity of different poisons from animal origin.

Dra. Angélica Santana is Professor Researcher at Centro de Investigación en Dinámica Molecular, UAEM. She is interested in understanding regulatory networks governing biological responses at the cellular, molecular and genomic levels. Her main area of research is Immunology, and collaborate with two researchers from the large group of scientists working on natural products at Universidad Autónoma del Estado de Morelos. She also participates in several student committees working on Natural Products and she is Co-director of the PhD student Veronica Núñez.

Martha Navarro studied his Bachelor at Universidad Autónoma Metropolitana (Iztapalapa). Part of the experimental work of her Bachelor Thesis was performed at Laboratorio de Enfermedades Neurodegenerativas, at Instituto Nacional de Neurología y Neurocirugía with Dra. Juana Villeda.

Dra. Angelica Berenice Aguilar Guadarrama is Professor Researcher at Centro de Investigaciones Químicas, UAEM. She is interested in the phytochemical study of Mexican plants, some of them used in Mexican Traditional Medicine. The main goals of her investigations are determination of chemical structure of secondary metabolites and the establishment of the biological activity of extracts and compounds on in vitro assays.

Dr. Gabriel Navarrete Vazquez received his Ph.D. degree in medicinal chemistry from the Universidad Nacional Autónoma de México. He serves as a full-time Professor of Organic and Medicinal Chemistry at Facultad de Farmacia, UAEM. His scientific production focuses on the rational design, preparation of bioactive synthetic and natural compounds, the study of their pharmacological actions, and the structure-activity relationships, with more than 111 publications and $\mathrm{H}-$ index $=28$. His research group is interested in the microwave-assisted organic synthesis, in silico PD/PK-ADMET predictions, molecular docking, and medicinal chemistry of azaheterocycles.

Dra. Irene Perea Arango is Professor Research at Centro de Investigación en Biotecnología, UAEM. Dra. Perea Arango's research includes aspects of plant tissue culture, genetic transformation, and biotechnology techniques. Her current research interests include the exploration of novel approaches of biotechnological technologies to enable medicinal plant biology research for production of secondary metabolites improvement. Her interests also include the use of biotechnological strategies for in vitro conservation, plant breeding and utilization of medicinal plants.

Dr. Ismael León Rivera received his Bachelor in Chemistry, M. Sc., and Ph.D. degrees at Facultad de Química, UNAM. Dr. Ismael León is Professor Researcher at Centro de Investigaciones Químicas, UAEM. His research interests are the isolation, characterization, and evaluation of the neuroprotective activity of saccharides from medicinal plants (Ipomoea species) and mushrooms (Ganoderma species).

Cite this article: Núñez-Urquiza V, Villeda-Hernández J, Montiel-Arcos E, Tello I, Campos-Peña V, Herrera-Ruiz M, et al. Evaluation of the Anticonvulsant, Anxiolytic, Sedative, and Neuroprotective Activities of Polysaccharides from Mycelium of Two Ganoderma Species. Pharmacogn J. 2021;13(5): 1161-1173. 